\title{
Recent advances in materials science: a reinforced approach toward challenges against COVID-19
}

\author{
Abhinav Saxena $^{1} \cdot$ Deepak Khare $^{1} \cdot$ Swati Agrawal ${ }^{1} \cdot$ Angaraj Singh $^{1} \cdot$ Ashutosh Kumar Dubey $^{1}$
}

Received: 2 January 2021 / Accepted: 27 January 2021 / Published online: 22 February 2021

(C) Qatar University and Springer Nature Switzerland AG 2021

\begin{abstract}
With the recent COVID-19 pandemic, medical professionals and scientists have encountered an unprecedented trouble to make the latest technological solutions to work. Despite of abundant tools available as well as initiated for diagnosis and treatment, researchers in the healthcare systems were in backfoot to provide concrete answers to the demanding challenge of SARS-CoV-2. It has incited global collaborative efforts in every field from economic, social, and political to dedicated science to confront the growing demand toward solution to this outbreak. Field of materials science has been in the frontline to the current scenario to provide major diagnostic tools, antiviral materials, safety materials, and various therapeutic means such as, antiviral drug design, drug delivery, and vaccination. In the present article, we emphasized the role of materials science to the development of PPE kits such as protecting suits, gloves, and masks as well as disinfection of the surfaces/surroundings. In addition, contribution of materials science towards manufacturing diagnostic devices such as microfluidics, immunosensors as well as biomaterials with a point of care analysis has also been discussed. Further, the efficacy of nanoparticles and scaffolds for antiviral drug delivery and micro-physiological systems as well as materials derived from human tissues for extracorporeal membrane oxygenation (ECMO) devices have been elaborated towards therapeutic applications.
\end{abstract}

Keywords COVID-19 $\cdot$ Nanotechnology $\cdot$ Detection $\cdot$ Biomaterials $\cdot$ Treatment $\cdot$ Antiviral $\cdot$ Protection

\section{An introduction to COVID-19}

Corona virus is spherical-shaped enveloped RNA with club shaped glycoprotein [1]. The human corona virus $(\mathrm{HCoV})$ are of four types such as alpha $(\alpha)$, beta $(\beta)$, gamma $(\gamma)$, and delta ( $\delta$ ) [2]. The $\alpha$ and $\beta$ corona viruses are originated from mice, bat, and swine, and found to be pathogenic. Whereas, birds and wheal are the intermediate host for $\gamma$ and $\delta$ corona viruses, respectively [3]. All four $\alpha, \beta, \gamma$, and $\delta$ corona viruses have several subtypes. Among all categories, $\beta$ corona virus affect human beings, while others influence animals such as, cat, mice, pigs, and dogs [4]. In 2001, few cases $(\sim 500)$ with flulike symptoms were reported. Among them, approximately 20 cases were identified as corona virus strain. It was categorized as subtype of $\beta$ corona virus and later renamed as severe acute respiratory syndrome (SARS-CoV) [5]. In 2003, the cases of

Ashutosh Kumar Dubey

akdubey.cer@iitbhu.ac.in

1 Department of Ceramic Engineering, Indian Institute of Technology (Banaras Hindu University), -221005, Varanasi, India
SARS-CoV have been reported in Hong Kong, Singapore, Thailand, and the United States of America [6]. Worldwide, around 8200 patients with fatality rate of approximately $11 \%$ were reported as SARS-CoV infected [7]. After a decade (in 2014), a few cases with similar symptoms like SARS-CoV were detected in Saudi Arabia, and renamed as middle east respiratory syndrome (MERS-CoV) [8]. The MERS-CoV has been reported as more infectious than SARS-CoV [9]. The mortality rate for MERS-CoV has been found to be approximately $35 \%$ [10]. The existing antivirus vaccines such as lopinavir/ritonavir, and griffithsin were used to control the infection of both SARS-CoV and MERS-CoV. In December 2019, a novel corona virus has been identified in Wuhan, China, with similar symptoms of SARS-CoV/MERS-CoV which was named as SARS-CoV-2 [11]. Later, it was named as novel coronavirus disease-2019 (COVID-19) by the World Health Organization (WHO). The source and intermediate host is still unclear. Bats are reported as the natural reservoir for COVID-19. While, Zhou et al. [12] reported pangolin as the host for COVID-19. It has been found that the novel SARS-CoV-2 is more effective and susceptible to frequent transmission than SARS-CoV and MERS-CoV. Due to the 
absence of proper vaccine and higher transmission rate, WHO declared the novel SARS-CoV-2 as "pandemic". The genome study of SARS-CoV-2 confirms that it has approximately $79 \%$ and $51.2 \%$ similarity with the genome of SARS-CoV and MERS-CoV, respectively [12]. The genome size for SARS-CoV-2 has been reported to be about $29.9 \mathrm{~kb}$. Whereas, SARS-CoV and MERS-CoV possess genome of 27.9 and $30.1 \mathrm{~kb}$, respectively [13]. The SARS-CoV-2 has an enveloped structure with 6-11 open read frames (ORFs) [14]. The main function of ORF is the translation of proteins.

It was found that COVID-19 has high transmission rate as compared to SARS-CoV and MERS-CoV [15]. It has been demonstrated that COVID-19 infection is more hazardous on old age people and severe illness patients like, cardio and diabetes [16]. The old age (65-75 years old) COVID-19 patients have about 90 times higher risk of death as compared to younger (18-29 years old) patients [17]. The COVID-19infected patients with cardiovascular diseases has $\sim 37.5 \%$ mortality rate [18]. An American report on 393 patients suggested that about $52 \%$ of infected patients have hypertension [19]. It has been reported that diabetes patients with COVID19 infection have higher risk of infection as compared to normal patients. A Chinese report of 150 patients mentioned that approximately $16 \%$ of infected patients have diabetes [20]. Another study reported that COVID-19-infected patients with diabetes have three times higher mortality rate as compared to normal patients [21].

With this perspective, various scientific platforms have been in rigorous work load to cope up with the current outbreak as well as to immediately provide solutions. Materials science field is also painstakingly been providing leading edge technological solutions to the current pandemic. Toward this end, the present article discusses the in-depth applications and prospects of materials science to withstand the COVID-19 challenges.

\section{Impact of materials science toward countering viruses}

COVID-19 virus infects the human beings through different routes such as, direct contact, food, blood, air, and water. Primarily, the virus interacts with the cells through the interlinking between a specific cell receptor named angiotensin-converting enzyme 2 (ACE2) receptors and S protein, present in the virus [Fig.1] [22, 23]. After entering the host cell, the virus reacts with the intracellular organs, synthesize RNA, and consequently, generates proteins which reorganizes and produces new viruses in the host cells which releases after cell death (Fig. 1) [22, 23]. Therefore, the infection of corona virus can be reduced by inhibiting the interaction between angiotensin-converting enzyme 2 (ACE2) receptors and viral $\mathrm{S}$ protein. The adhesion of host cells and virus can be prevented either by managing ACE2 or by inhibiting cellular proteases which help in the interaction process of $\mathrm{S}$ protein with the host cells [23, 24].

Materials science offers better detection tools especially for the isolation of the nucleic acids and proteins. For example, the magnetic particles can isolate the nucleic acid and proteins from the biological samples [25]. These nucleic acid and proteins can further be separated out using magnetic field [25]. In addition, microfluidics with the isolation techniques allows rapid detection of viruses with fewer amounts of reagents [26]. Magnetic particle-based microfluidics is also suggested to offer the isolation of viruses [27]. Rapid detection of viruses hinders its spread and therefore, materials coupled with immunoassays and PCR tests for nucleic acid amplification are reliable for on-site detection of viruses (Fig. 2) [22].

Material science plays an important role in the development of engineered small molecules which has a vital aspect in the development of broad spectrum antiviral drugs and targeted drug delivery. These small molecules may also be used to mimic receptors on cell membrane to inhibit viral entry. The materials science has remarkable contribution in terms of the development of nanoparticles, acting as entry inhibitors and replication inhibitors and also helps in antiviral antigen delivery platforms due to their size. Nanomaterials act as effective carriers and delivery agents for vaccine and drugs which play a crucial role in the development of nanomedicine [28]. Also, material science has a central role in developing various medical equipments like, ECMO devices and ventilators.

\section{Viral protection}

Materials science plays a crucial role in the effective protection against COVID-19 virus by various means such as isolation, disinfection, and inactivation [23, 29]. Personnel protective equipment (PPE) kits, such as protective suits, face shields, masks, gloves, and goggles, helps in physically isolating the human body from viral infection to stop the spreading of COVID-19 virus [22, 30]. Zhang et al. [31] fabricated an efficient air filter based on ionic liquid polymer (ILP) composite which was distributed on the spongy network of melamine-formaldehyde (MF). Such type of masks possesses nanofibrous filter which can filter out even nano-sized particulates and allow clean air for comfort in breath [Fig. 3 (a)] [31, 33]. These filters can remove particulate matter of $\mathrm{PM}_{2.5}$ with the removal efficiency higher than $99 \%$ [31, 33]. In another study, a specialized mask was prepared by combining a layer of cotton along with a layer of chargeable natural silk (chiffon) [32] where, the removal mechanism involves the combined action of mechanical and electrostatic filtration (Fig. 3(b)).

Tang et al. [22] suggested that masks should also have a drug incorporating feature to treat the infected patients and 


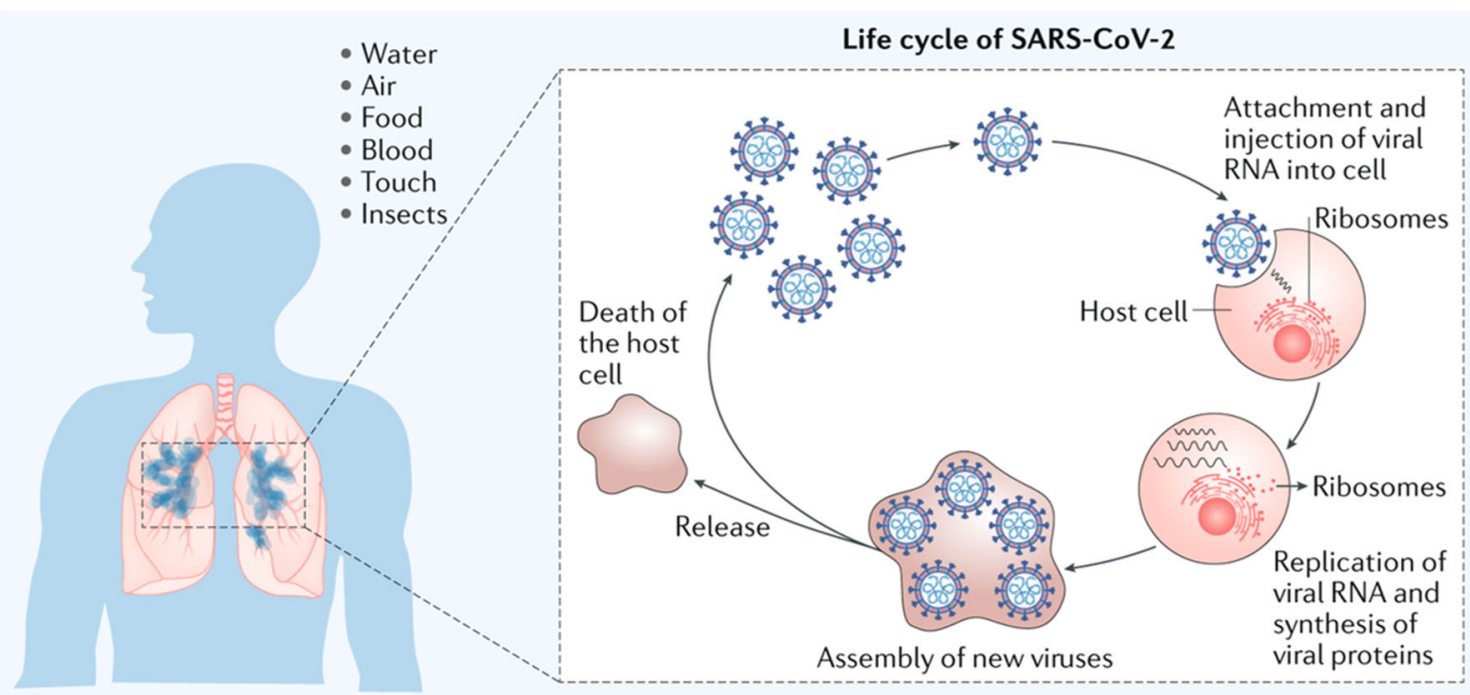

Fig. 1 Illustration of various routes for COVID-19 virus transmission and the life cycle of COVID-19 through the host cell-virus interaction [22] (Reproduced with permission from Springer Nature).

stop the spreading of COVID-19 virus. Recently, we faced the problem of shortage of PPE kits during COVID-19 pandemic. Therefore, the development of reusable masks, gloves etc. is in continuous thrust. The surface treatment or surface coating provides self-cleaning ability to the masks, gloves, and protective suits and consequently, made these protective tools reusable [34, 35]. Atab et al. [34] fabricated a polymeric membrane made of polyamide with intrinsic hydrophobicity which can easily bounce off the aqueous droplets of virus. Apart from hydrophobic surfaces, sunlight sterilization feature was also included in a membrane, as developed by Zhong et al. [35]. For this purpose, graphene-coated masks have been prepared with highly hydrophobic surface (inclination angle $141^{\circ}$ ) and excellent photothermal properties. Due to which, the temperature of the outer layer of mask reached to about 80 ${ }^{\circ} \mathrm{C}$ and consequently, becomes sterilized in sunlight [35].

\section{Nanotechnology approach}

Nanotechnological tools are well-known for their excellent physiochemical properties which can be controlled through flexible chemical functionalization. Nanotechnology has already been demonstrated as a successful tool to fight against
Fig. 2 Materials science platform for application toward virus detection via PCR (polymerase chain reaction) and antibody attachment to the virus [22] (Reproduced with permission from publisher)

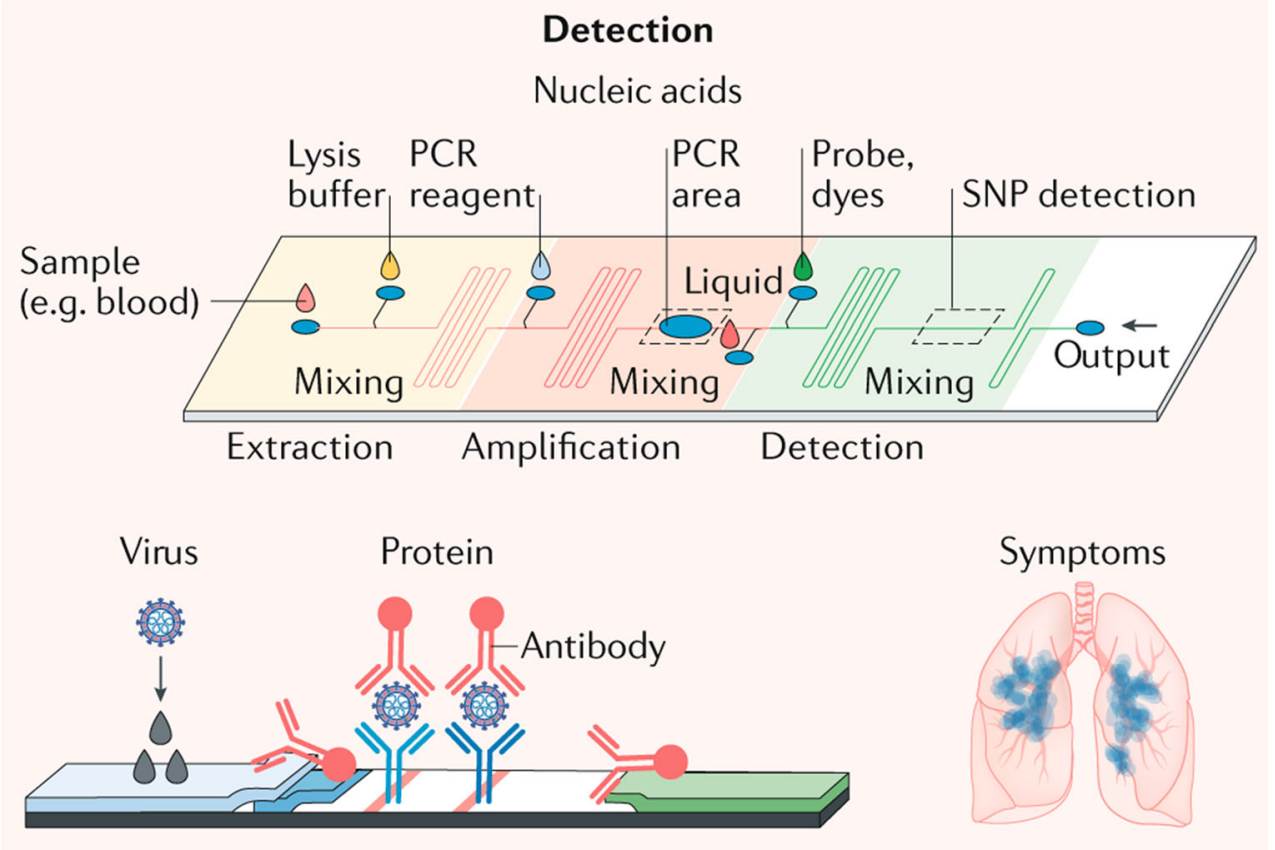




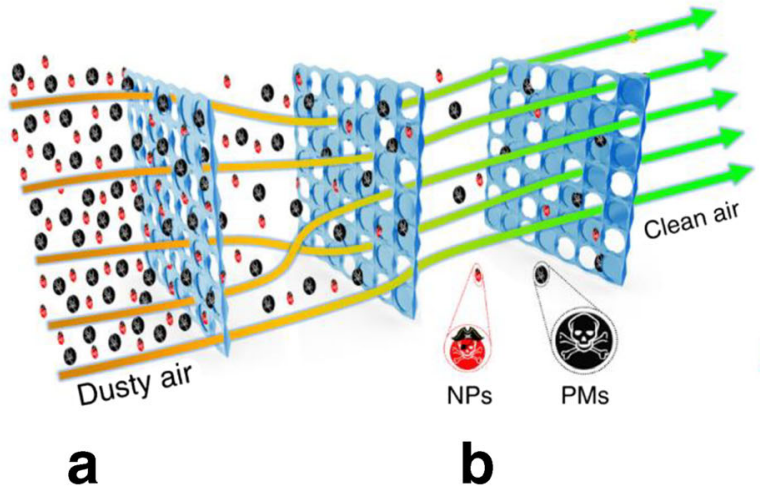

Fig. 3 Mechanism of matter removal using mask through various strategies. (a) Schematic description of ILP-MF-based air filter for removing particulate matter as well as nanoparticles through multiple layer

HIV and other viruses such as herpes and respiratory [36, 37]. The protective tools should be designed in such a way which do not only filter out the viruses but also should have the ability to decontaminate easily. Several methods have been suggested for disinfecting the detection surfaces and development of treatment or life-saving devices. Therefore, the potentiality of nano-sized materials for the battle against COVID-19 viruses is briefly summarized in subsequent sections.

\subsection{Nanomaterial-based filtration}

COVID-19 virus mainly is transmitted through respiratory droplets, released from the infected patients and preferably via nose. Therefore, specialized masks with excellent particulate matter removal efficiency are needed which can prevent the entering of smaller sized droplets as well as aerosols in human body [38]. Nanotechnology can help in fabricating nanoporous masks, which restrict the transmission of aerosols, released during sneezing or coughs and consequently, control the transmission and spreading of COVID-19 virus [39]. Graphene oxide has been reported as an inhibiter of the ATP activity of SARS [40]. Therefore, the coating of graphene oxide can be applied to the filter of masks or gloves, protective gown etc. to disinfect the virus. More recently, it has been reported that graphene coating improves the hydrophobicity of the surface of masks which restricts the viability of the virus on its surface [35]. In addition, such type of graphene-coated masks can be reusable due to its excellent photothermal properties which makes these masks self-sterilized in the exposure of sunlight [35]. 2D titanium carbide Mxene shows excellent adsorption capability of amino acids [41]. Due to which, such type of surfaces not only capture the virus but also inactivate the captured viruses $[23,41]$. Another author reported the photocatalytic property of Mxenes, which promote the degradation of adsorbate in presence of light and consequently, provide the self-cleaning ability to Mxene-coated gloves, masks, and protective suits $[23,42,43]$. The selection of commercially used fabrics at nanoscale, number of layers, and fit

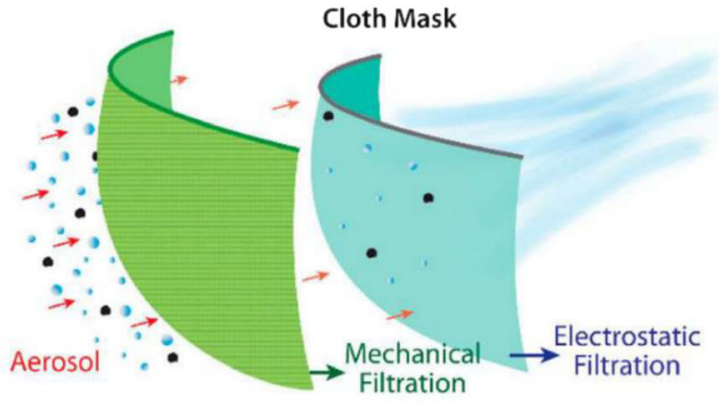

[31] (Open Access), (b) Multiple-layered filter, used to remove particulate matter by synergistic action of mechanical and electrostatic filtration [32] (Reproduced with permission from publisher).

are also important in designing the masks as the unfit masks and corresponding leakage results in about $60 \%$ of reduction in the filtration efficiency [32]. The filtration of air in the nosocomial environment is also important as the droplets or aerosols of about $1 \mu \mathrm{m}$ size remain in air for up to $12 \mathrm{~h}$ and can travel to 20 feet with strong sneeze [38]. For this purpose, buildings are generally installed with filter in HVAC (heating, ventilating, and air-conditioning) unit to limit the spreading of pathogens [44]. HEPA (high-efficiency particulate air) filters are commonly used to eliminate the smoke, dust, etc. in buildings which have also the ability to filter out the airborne viruses, bacteria, and fungi, present in the environment [45]. HEPA filters contains fine (dia.: 0.5-2.0 $\mu \mathrm{m})$ randomly oriented fibers which can remove airborne particles of size greater than $0.3 \mu \mathrm{m}$ diameter with excellent filtration efficiency (99.99\%) [45]. Carbon fiber ionizer, installed at the upstream of air filter, generates charged particles through corona discharge and capture the pathogens due to electrostatic interaction [46]. The viability of airborne viruses in air can also be controlled by the atomization of antiviral silver nanoparticles; however, this method needs further investigation by considering silver induced health hazards [47]. Indoor filters with palladium (nanoparticles)-titanium dioxide and vacuum ultraviolet irradiation-have been developed to filter and inactivate the filtered pathogens [48]. Similarly, nanofiltration and surface modification have been adopted for the removal of virus [49].

\subsection{Inactivation of viruses and disinfection of surfaces/surroundings}

COVID-19 becomes more contagious due to the contamination of used masks, gloves, respirators or floor, wall, ventilator, surgical tools, etc. at the hospitals or quarantine centers from where, these viruses can be easily transmitted via infected people [50]. Some of the specific metal nanoparticles are well-known for their excellent antiviral ability such as silver, gold, and copper oxide [51-53]. The protective coatings of 
these metallic nanoparticles can be applied on the commonly used surfaces or PPE equipment to inactivate the virus. Silver nanoparticles $(1-10 \mathrm{~nm})$ can preferably bind with the sulfur residues, present on the viral envelop and therefore, restrict the further binding of viruses with the host cells [51, 52]. Similarly, gold nanoparticles also bind with the virus particles and therefore, block the receptors of host cells [54]. Gold nanoparticles bind and break the disulfide bonds of the virus and thereby, inhibit the viral membrane interaction with the receptor of host cells [Fig. 4 (a)] [52, 54]. Copper oxide nanoparticles have the ability towards oxidative damage of the enveloped as well as non-enveloped viruses [53]. Although, the above mentioned metallic nanoparticles are toxic for the host cells/tissues at a certain level, however, the toxicity can be reduced by optimizing the particle size, doses, coating composition/dimension, etc. [56]. Such type of metallic coatings can be applied on the dressing strip, PPE kits, ventilators, doors, tables, etc. to minimize the spread of COVID-19.

Surfactants are other disinfecting agents for the inactivation of the viruses [57]. The most common surfactants which can be used for the protective coatings are N, N-dodecyl methyl polyethylenimine, cetylpyridinium chloride, nlauroylsarcosine, sodium lauryl sulfate, etc $[55,58,59]$. The coating of the N, N-dodecyl methyl polyethylenimine not only diffused the virus on its surface but also inactivate due to hydrophobic action (Fig. 4(b)) [55]. The membrane-active biosurfactant physicochemically interacts with the viruses and results in the rupture of their capsid and lipid membrane and thereby, damages the viruses [60]. These surfactant coatings can be applied for the safety of pharmaceutical tools, i.e., prevent against COVID-19 virus.

\section{Diagnosis of COVID-19}

\subsection{Nucleic acid based-detection techniques}

In the present COVID-19 crisis, rigorous safety measures have been implemented by various countries to recognize the infected people, isolate them, and monitor the spread of the virus. In this perspective, reverse transcription-polymerase chain reaction (RT-PCR), enzyme-linked immunosorbent assay (ELISA), and lateral flow assays (LFA) have been recognized as the leading alternatives to the biodetection in the current pandemic. However, each of these techniques has its limitations [61]. The latter two clinical testing standards are presently not
Fig. 4 Mechanisms of nanoparticles and surfactantinduced virus inactivation. (a) Gold nanoparticle interaction with the virus results in breakage of their disulfide bonds and consequently, inhibit host cell-virus interaction or infection [54] (Open Access). (b) Diffusion, immobilization, and inactivation of influenza virus on the $\mathrm{N}, \mathrm{N}$ dodecyl methylpolyethylenimine (surfactant)-coated surface [55] (Reproduced with permission from publisher)
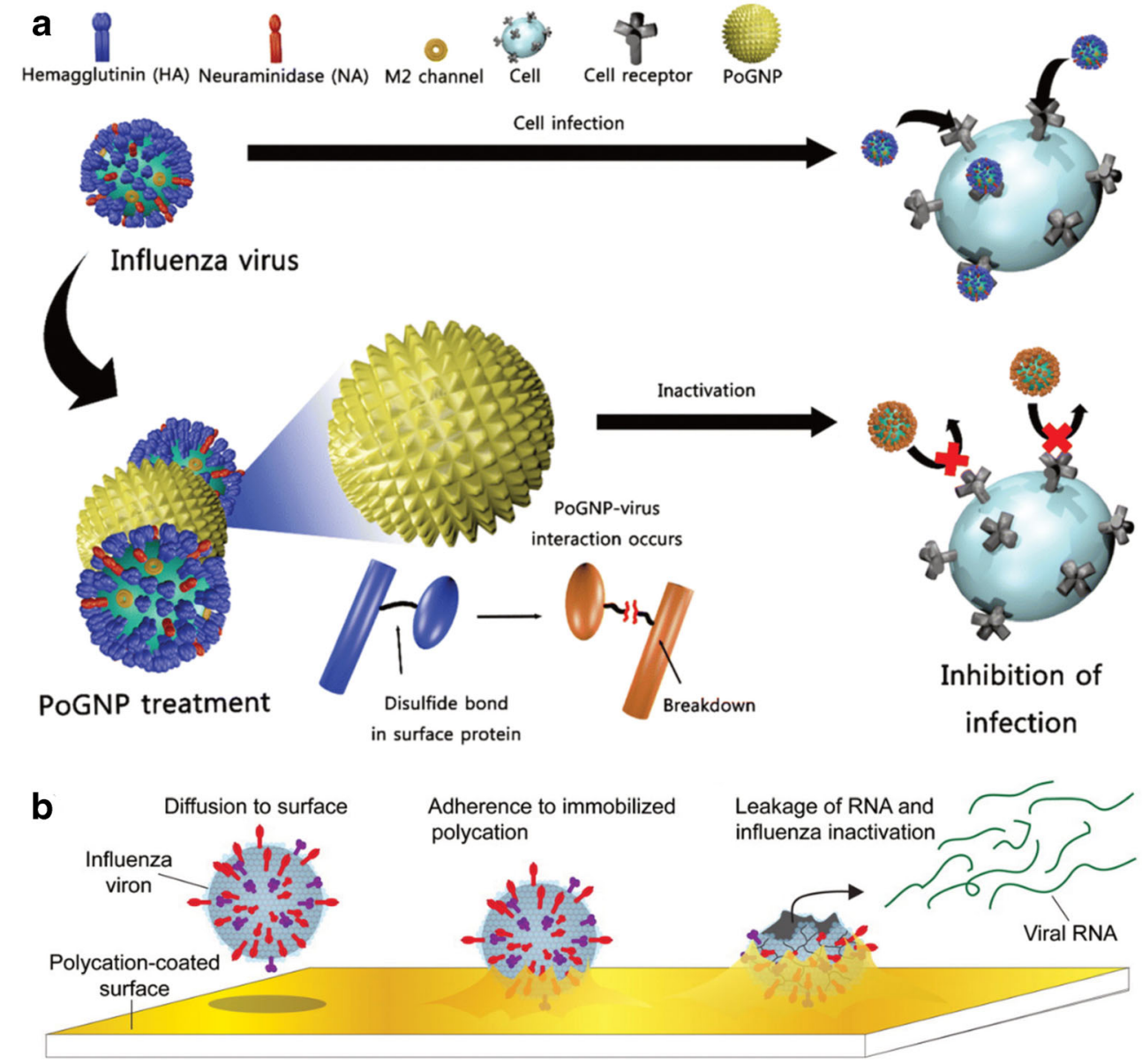
proposed by the World Health Organization (WHO) [62]. The real-time RT-PCR, which is currently common clinical testing means for COVID-19, has succeeded among the myriad of biodetection methods because of its excellent specificity to pathogens and resolution (limits of detection) [52]. In this technique, the single stranded DNA/RNA viruses are usually detected. In the current RT-PCR tests, 3 steps are undertaken. Initially, the biological samples are collected and treated chemically by lysing the membranes of the viruses releasing nucleic acids. These nucleic acids are then precipitated and are collected through centrifugation. Second, the collected RNAs are then transcribed using reverse transcriptase enzymes to form stable complementary DNA (cDNA). The cDNA are then thermocycled (sequential denaturation, annealing, and extension) to amplify the target sequences. Third, the target cDNA sequences are then detected via current/fluorescent probes, inserted in the reaction mixture through increased fluorescence which is directly proportional to the accumulation of target cDNA sequence. Therefore, by amplification of the target cDNA sequence, high resolution is established in the current RT-PCR tests. However, such tests have limitation, i.e., it requires infrastructural support for instrumentation set-up for processing and detection. The inaccessibility to these regions from the remote areas often leads to the limited sample collection and high risk to the spread of the virus. In addition, requirement of well-trained medical professionals as well as long time duration to provide the diagnosis are few of the disadvantages, associated with such tests. In these methodologies, virus isolation is required which is also a laborious procedure.

Overall, in medical biology, any biomolecule detection methodology (including RT-PCR) is constituted of three major parts [63]. First, the biosensors which consist of receptors (i.e., for identification of the biological samples) provide a recognition signal to the transducer (connected to the receptor). The transducer, in turn, converts this signal into a measurable electrical signal. The second part consists of methods to prepare the biological sample. Sample preparation primarily depends on the conditions, required for the detection as well as on the scientific principle, followed by the sensors (e.g., microfluidics, electronic measurement, temperature dependence, etc.). Finally, the interpretation of the results is carried out. The first and last part primarily belongs to the medical professionals. Medical professionals examine the validity and conformity of the samples with specified protocols. The diagnosis corresponding to the final results is only authorized by a certified medical doctor. This is the general medical procedure utilizing robust sophisticated instruments with precise measurements of the large number of samples.

These diagnostic methods are, therefore, time consuming (i.e., from sample collection to the interpretation of the results). The best alternative to these methodologies is a point of care (POC) systems, which offers accurate and rapid results [52, 63]. Also, they are useful to provide the diagnosis in the case of emergency conditions as compared to conventional laboratory testing process. This reduces the risk of spread of the disease. In addition, access to remote areas becomes feasible. The POC biosensors are such alternatives.

Recently, a rapid detection methodology ( $30 \mathrm{~min})$ which does not require such complex procedures, the loop-mediated isothermal amplification (LAMP) has been tested [64], [65]. This test is similar to PCR tests, except the amplification of target DNA takes place at same temperature as compared to that in PCR tests. Therefore, thermal cycler, one of the instruments utilized in PCR tests, is not required in the LAMP process [65]. LAMP along with reverse transcriptase enzyme (RT-LAMP) assays can provide rapid, user friendly, and cheaper tests as compared to qRTPCR tests [64]. In addition, tests can be undertaken at wide temperature and $\mathrm{pH}$ ranges along with the acceptance of nonprocessed biological samples. The test also provides flexibility, specificity, and sensitivity equivalent to the current PCR tests. The amplification and detection steps occur at the similar time in the same test tube by incubating the samples (target DNA and RNA) at $60-65^{\circ} \mathrm{C}$ along with specifically designed biomarkers and Bst DNA polymerase [65].

Biomaterials also present preferable POC approaches towards diagnosis such as manufacturing of disposables, nasal, and buccal swabs for collection of DNA samples which can be preserved over the long duration of time [52]. Recently, 3Dprinted nasopharyngeal swabs (nasal) were developed, tested, and validated by Formlabs (USA) [66]. In India, Reliance Industries in collaboration with Johnson \& Johnson also started manufacturing test swabs since, May, 2020, which was validated and approved by the National Institute of Virology, Pune [67]. Biomaterials also present POC target detection of DNA sequences using quantum dots [68]. In the study, quantum dots were utilized as oligonucleotide probes to detect target sequences of viral nucleic acids. In addition, biomaterials are proposed to break the ethos of detection methods, which require sophisticated instrumentation as an original methodology, are in progress that can extract the viral genetic material from complex biological samples and thereby, amplifying the target sequences which can be viewed simplistically [52, 69-71]. It has been reported that gold nanoparticles and quantum dots are suggested to be excellent optical probes/biosensors, based on the phenomenon of localized surface plasmon resonance (LSPR) to detect the biomolecules and their interactions $[72,73]$. The surface of gold nanoparticles changes its color, size, shape, and surface chemistry, based on the characteristic of attached biomolecule which can be detected via spectral shift. The spectral shift occurs due to the change in the dielectric property of the surface of nanoparticles. These shifts can be observed through the calorimetry [74]. Lateral flow assays using colloidal gold nanoparticles for the detection of viral RNAs of COVID-19 have been approved by WHO [75]. Quantum dots (QDs) are fluorescence semiconductor nanoparticles. They are stable and 
bright as compared to organic dyes. In addition, these quantum dots are excited by single wavelength and reveal different colors depending on their size. Biocompatible quantum dots are already being used as biomarkers for cells and tissues. Magnetic nanoparticles of zinc ferrite, containing functionalized surfaces with carboxyl containing polymers, have been reported to isolate the RNA of COVID-19 [76]. Zinc ferrite is easy to prepare, biocompatible, chemically stable, and possesses magnetic properties. The carboxyl group modified on the surface of zinc ferrite nanoparticles easily attract and adsorb the viral RNA and thereafter, these can be further employed in RT-PCR tests $[75,76]$. Therefore, using this process, the laborious procedure to extract the viral RNA, used in PCR tests is not required. Recently, detection kits for RNA extraction from the biological samples has also been developed and launched by Sree Chitra Tirunal Institute for Medical Sciences and Technology, India in collaboration with Agappe Diagnostics Ltd., India [77]. These detection kits use magnetic nanoparticles which can easily encapsulate the viral RNAs from the biological samples.

CRISPR/Cas (clustered regularly interspaced short palindromic repeats/CRISPR-associated)-based detection of viral nucleic acid has been another sensing methodology. It has been developed into a more specific nucleic acid detection methodology, i.e., SHERLOCK (specific high-sensitivity enzymatic reporter unlocking) having calorimetric readout based on fluorescence and lateral flow based assays [78]. In this methodology, Cas (CRISPR associated) proteins become activated upon sensing of target RNA and in turn, they split the fluorophore-RNA-Quencher reporter molecule into a fluorophore [Fig. 5 (a)] [52]. Another detection procedure for COVID-19 is based on the calorimetric method which uses the RNA toehold switch connected with platform of paper having cell-free proteins which attaches the target RNAs (Fig. 5(b)) [52]. The RNA toehold switches are synthetic RNA molecules along with toehold and regions of coding. The barrier between the two is hairpin structures that sequestrate the binding site for ribosome and thereafter, start codon. The target RNA sequence attaches to the toehold region which subsequently, unfolds the hairpin to further allow for binding of ribosome and thereafter, a particular expression for gene is observed. Overall, CRISPR and RNA toehold detection methodologies utilize the enzymatic reporter system which exponentially amplifies the signal intensity upon accumulation of target sequence as compared to conventional nucleic acid probes. Therefore, when these systems are RNA specific, it can further be suggested to detect very low concentration of target RNAs, especially in the case of COVID-19.

\subsection{Antibody/antigen-based detection techniques}

The above detection methodologies directly detect the viral RNA and DNA. Another strategy is the detection of antigens/antibodies which are generated by the patient's immune system against viral diseases. ELISA is one of the tests to detect the antibodies produced against antigens in blood in response to the viral infection. In this methodology, the antigens are immobilized on the solid surface containing biological sample (i.e., blood) and further the linked enzyme with the binding of the antigen and antibody is also added. Thereafter, the incubation is followed giving a suitable product created due to the antibody-antigen binding which is quantifiable.

Electrochemical immunosensors have been recognized as a suitable POC device because of their portability, cost effectiveness, simplicity, user friendliness, and real-time data interpretation (Fig. 6) [80]. These biosensors are basically classified in the category of the affinity-based biosensors. Immunosensors, generally, use the antibody and antigen (covalent/non-covalent) binding mechanism as biological recognition stage which is further coupled with a transducer to produce a measurable signal $[78,81]$. It is comprised of a solid matrix where the antibodies or antigens are immobilized. The surface of the matrix contains the optically sensitive materials, piezoelectric materials or membranes such that they change their physical or optical properties because of the formation of immunocomplex (antibody-antigen complex). These changes in properties can be conveyed in the form of signals such as optical evanescent wave, surface plasmon resonance, fluorescence, and chemilumenescense [82]. Various nanomaterials and nanocomposites such as quantum dots [83-85], nanoparticles of metals [86-89], and conducting polymers [90-93] have been utilized to develop immunosensors. The use of these materials is primarily due to their highly selective nature to bind the specific ligands and also due to the amplification of signal generated due to the formation of immunocomplex. Immunosensors primarily are of two types, i.e., labeled and non-labeled [80]. In the non-labeled immunosensors, the detection of the analyte depends on the physical properties while in a labeled immunosensors, highly sensitive label (dye) is utilized as a detectable reagent whose properties change with respect to those of immunocomplex. Impedimetric immunosensors are one of the non-labeled sensors which utilize the change in the conductance/resistance of the immunocomplex and convey the signal in the form of Nyquist plot (Fig. 7). Figure 7(c) depicts the impedimetric immunosensor having an electrode which is comprised of antibody coupled with nitrogen and sulfur codoped graphene quantum dots and gold embedded polyanline nanowires. Using the pulsed electric field, the change in the conductance of the electrode can be observed when the virus binds with the antibody. Whispering gallery modes (WGM) biosensing platform excited by microcavities have been suggested to have very low detection limit. In addition, they are optically very sensitive as well as they are label free (Fig. 7(d)). When combined with the plasmonic resonance phenomenon, their detection limit is lowered, i.e., up to the detection of single RNA molecule.

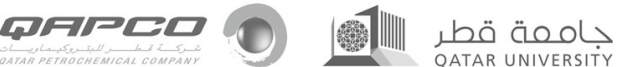
QATAR UNIVERSITY Springer 
Fig. 5 Schematic approaches for the diagnosis to detect SARSCoV-2 nucleic acid. (a) Detection based on CRISPR/Cas methodology: Upon activation of Cas proteins in the vicinity of target RNA sequences (blue), it splits the fluorophore-RNA-quencher reporter molecules. The detached fluorophore is detected via increase in fluorescence. (b) Sensors with RNA toehold switch which unfolds on sensing of target RNA sequences to further bind ribosomes. These ribosomes produce enzymes with messenger RNA (mRNA) sequences which thereby, convert substrate into colored product. (c) Multi-part nucleic acid (MNA)-based enzymes on sensing of target RNA sequence congregate and thereafter, splits the fluorophorequenched reporter molecules [52] (Reproduced with permission from publisher)
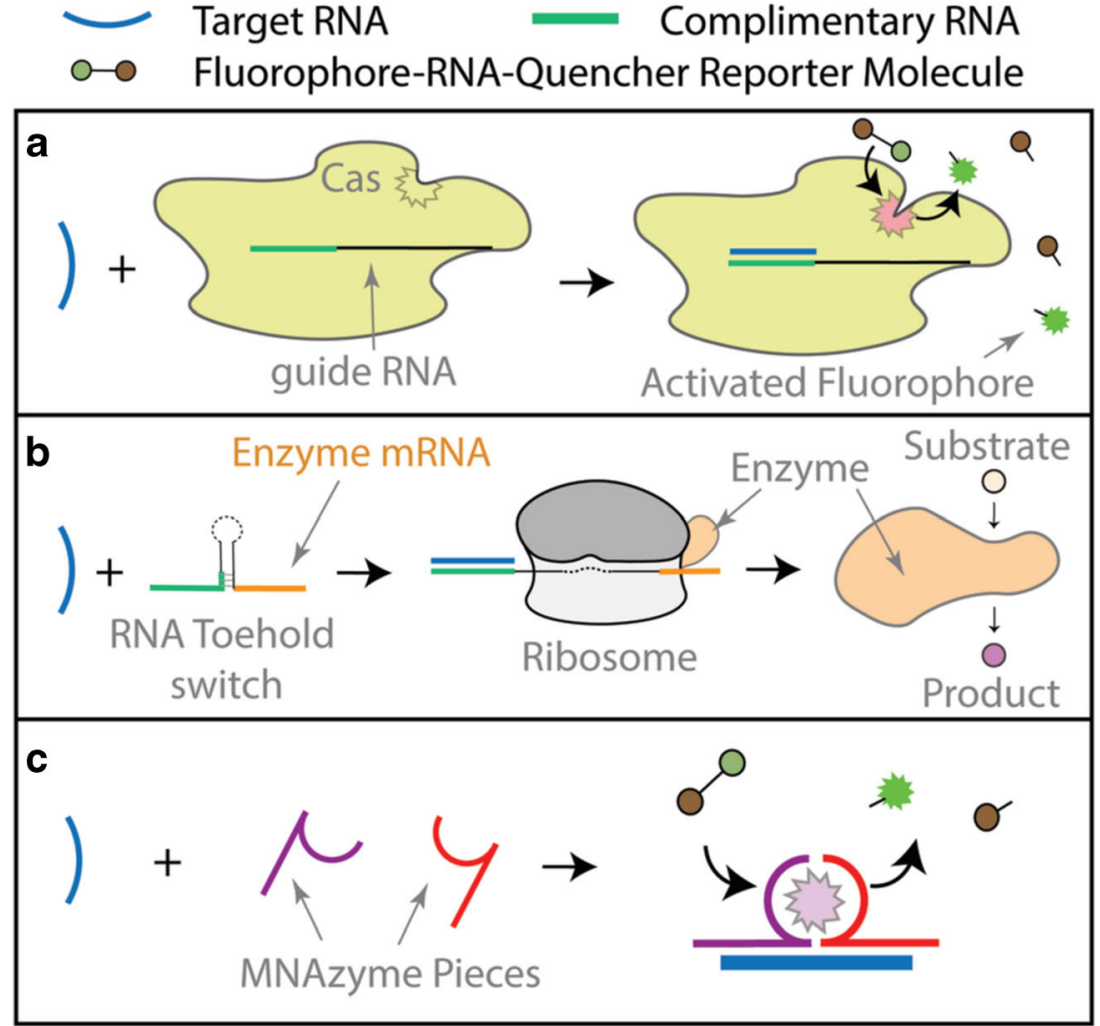

Weng and Neethirajan et al. [98] developed a labeled immunosensor, i.e., based on fluorescence resonance energy transfer (FRET) mechanism to detect the infectious bronchitis virus (IBV), a type of coronavirus. In this microfluidic assay, probes of antibodies are labeled with fluorescence dye and $\mathrm{MoS}_{2}$. In presence of the target virus (IBV), antibody binds with the antigen forming a complex and thereby, the fluorescence dye is quenched due to the presence of $\mathrm{MoS}_{2}$ to provide a measurable signal. Piezoelectric biosensors are also developed which are based on the changes in the frequency of piezoelectric quartz crystal (PQC) when the antibodyantigen binding happens [99]. The receptor (i.e., antibody) is immobilized on the PQC surface and the specific binding of the antigen with the antibody changes the mass of the PQC and thereby, decrease the corresponding oscillating frequency which is a measurable signal.

The antibody-conjugated gold nanoparticles incorporate the antigen-RNA-biotin reporter molecules which can be
Fig. 6 A schematic description of nanomaterials coupled electrochemical immunosensor [79] (Reproduced with permission from publisher)

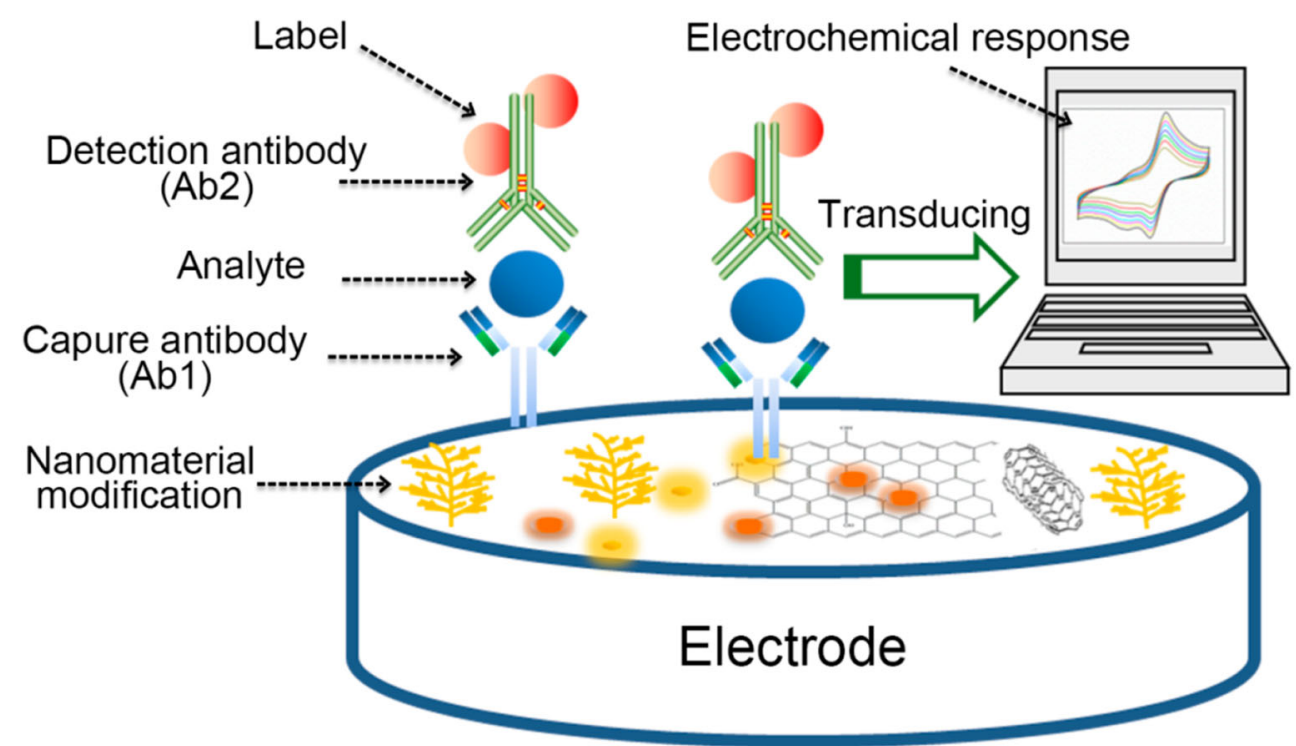


a
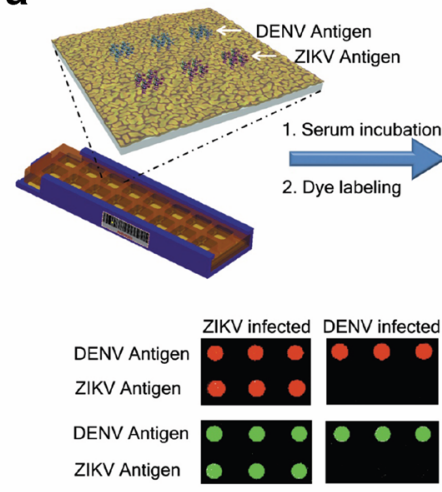

C

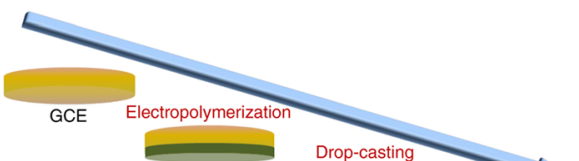

PAni
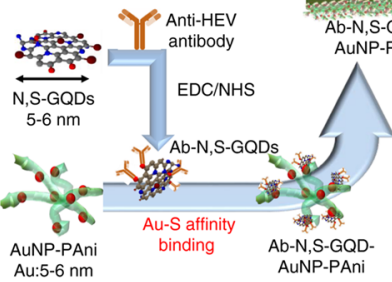

Au:5-6 nm

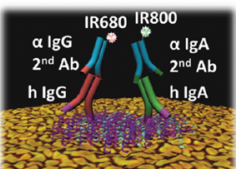

3. Reading

\& analysis

Control

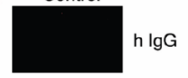

$h \lg A$ b

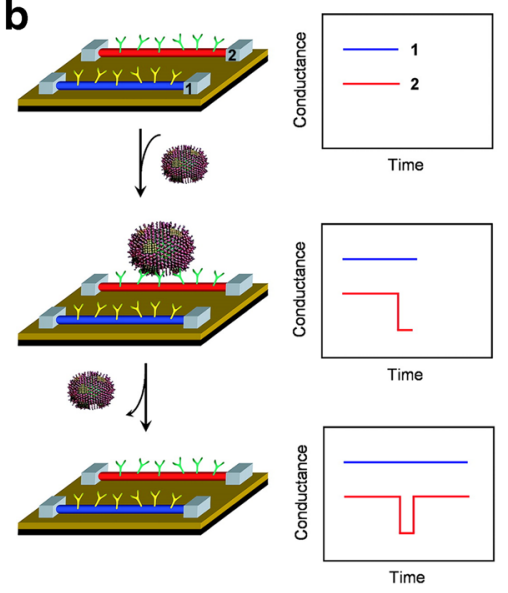

d

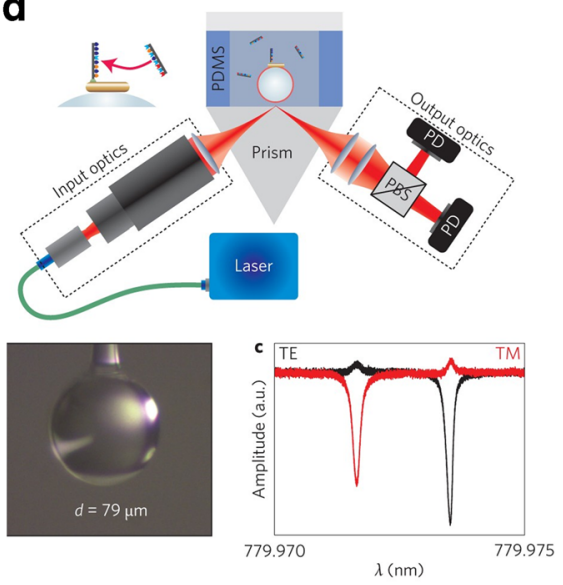

Fig. 7 Virus detecting methodologies, utilizing materials: (a) Multiplexed microarrays with plasmonic gold (pGold) nanostructures and near-infrared fluorescence molecules having Zika and dengue antigens (triplicate). Human serum containing antibodies against Zika (ZIKV) and dengue (DENV) viruses are discharged in the microarrays. Thereby, antibodies get captured by the antigens on the microarrays. Antibodies are tagged with a mixture of fluorescent dyes [anti-human immunoglobulin G-infrared fluorescent dye 680 (IgG-IRDye680) and immunoglobulin A-infrared fluorescent dye 800 (IgA-IRDye800)]. The microarray (biochip) is thereby scanned in a fluorescence reader indicating the binding of antibodies and antigens [94] (Reproduced with permission from publisher). (b) Antibodies, embedded in nanowires binds with the viruses and thereby, change in the conductance of the nanowires is observed [95] (Copyright (2004) National Academy of Sciences, U.S.A.). (c) Pulse-induced impedimetric biosensors using electrode matrix of nitrogen and sulfur co-doped graphene quantum dots (GQDs) and polyanaline nanowires embedded with gold (AuNP-PAni) to detect the hepatitis E virus (HEV). The HEV is captured through nitrogen-linked anti-HEV antibody $(\mathrm{Ab})$ attached to sulfur co-doped GQDs and AuNpPAni (Ab-N, S-GQDs@AuNP-PAni) while a pulsed external E-field is applied to observe the impedimetric response [96] (Open Access). (d) Plasmonic gold nanorod-based biosensors to sense the single RNA molecule [97] (Reproduced with permission from publisher). Abbreviations: EDC, 1-ethyl-3-(3-dimethylaminopropyl) carbodiimide hydrochloride; GCE, glass carbon electrode; NHS, N-hydroxysuccinimide; N, SGQDs, nitrogen and sulfur codoped grapheme quantum dots; PBS, polarizing beam splitter; PD, photo-detector; PDMS, polydimethylsiloxane detected via lateral flow dipsticks which are commercially available. Positive and negative tests from these complex assays are relatively simple as they can be detected via position of dark purple line on a paper strip. These detection methodologies are in progress for COVID-19 tests $[100,101]$. Various biosensors and transducers have been developed for nucleic acid detection utilizing nanostructured surface which is activated toward antigens/antibodies as well as smart materials to detect the specific DNA sequence [52]. In addition, synthetic multi-component nucleic acid enzymes (MNAzymes) are one of the alternatives with efficient sensing capability as they congregate due to the presence of target RNA sequences (Fig. 5(c)). Recently, graphene-based field effect transistor (FET) has been developed as an on-site rapid detection biosensing device which is linked to the antibody formed against protein spike of SARS-CoV-2 in culture medium (limit of detection, LOD: $1.6 \times 101 \mathrm{pfu} / \mathrm{mL}$ ) and samples (LOD: $2.42 \times 102$ copies $/ \mathrm{mL}$ ) [102].

Nanomaterials comprised of biological as well as synthetic molecules with excellent electrical and optical properties have been used recently to develop nanobiosensors $[23,103]$. These biosensors generally use nanomaterials as bioreceptor to 
selectively recognize the analyte. Gold nanoparticles (Au NPs) electrocatalyzed hydrogen evolution reaction (HER) conjugated with specific antibodies were used to detect the cancer circulating cells (CTCs) [104]. With this property of Au NPs, it can also be used to detect the viruses with known antigens and antibodies. In a recent report, solid-phase isothermal recombinase polymerase amplication (RPA) methodology has been utilized to detect Citrus tristeza virus (CTV) found in plants [105]. In this study, gold nanoparticles coupled with DNA strands were placed on the electrode surface which further detects the in-situ amplified CTV (amplification of p20 gene, 387-bp, a characteristic feature of CTV) via RPA assay [Fig.8]. The electrochemical impedance spectroscopy (EIS) $\left[\mathrm{Fe}\left(\mathrm{CN}_{6}\right)^{4-} / \mathrm{Fe}\left(\mathrm{CN}_{6}\right)^{3-}\right.$ redox system] was utilized to analyze the in-situ amplified CTV target which can detect $1000 \mathrm{fg} / \mu \mathrm{L}$ of nucleic acid. BioMEMs (biomedical microelectromechanical systems) are one of the mechanical transducers being continuously researched for biosensor applications, examination, and recognition of biological molecules, drug delivery applications, and lab on a chip system for implantable biosensing. However, MEMS still have a long way to revolutionize the field of detection with respect to viruses, especially for practical purposes.

\subsection{Medical equipment-based detection}

Diagnostic instrument such as, computed tomography (CT) which is X-ray imaging equipment, provides the images of the internal organs of the human body in 3D. These images can be further used for the identification, detection, and analysis of the viral infections such as COVID-19. For example, an infected lung with COVID-19 can be depicted having shadowy patches as well as in pulmonary tracks/bands, these patches are visible in the images, provided by CT. In addition, equipment such as ultrasonic (ultrasound) system provides real-time images of the area where the work piece is acoustically coupled with the body. It can, therefore, be enabled to provide the real-time images of the lungs which are further useful for the diagnosis of COVID-19. Other sophisticated instruments such as magnetic resonance imaging (MRI), single-photon emission computerized tomography, and positron emission tomography are also utilized for efficient imaging of the internal environment of the human body with high precision. However, well-trained medical staff in handling such instruments are scarcely available, therefore, convenient on-sight detection instruments are to be developed to have accurate results.

\section{Therapeutic approaches and applications}

It is known that viruses are made up of genetic materials, few structural proteins, and envelopes (in cases of enveloped viruses). The genetic material of virus is prone to mutational changes [106]. Viruses are dependent upon host cell machinery for their various functions such as, replication. Bacteria can be treated with antibiotics because they have well understood structures and predictable replication mechanisms. However, such mechanisms for viruses vary from type to type and species to species.

The currently available antiviral drugs are usually effective against limited group of viruses [107]. Since 1963, only 90 drugs have been categorized under classification of effective antivirals for only 9 infectious viruses [108]. Therefore, requirement to the wide range of antiviral drugs to target several viruses of different types such as respiratory viruses, mosquito borne, tick borne, or unknown vector viruses are growing [109]. The development of such effective antivirals can provide multipurpose solutions to prevent further pandemics in the future. Materials science has played a vital role in the development of various treatment procedures for diseases like
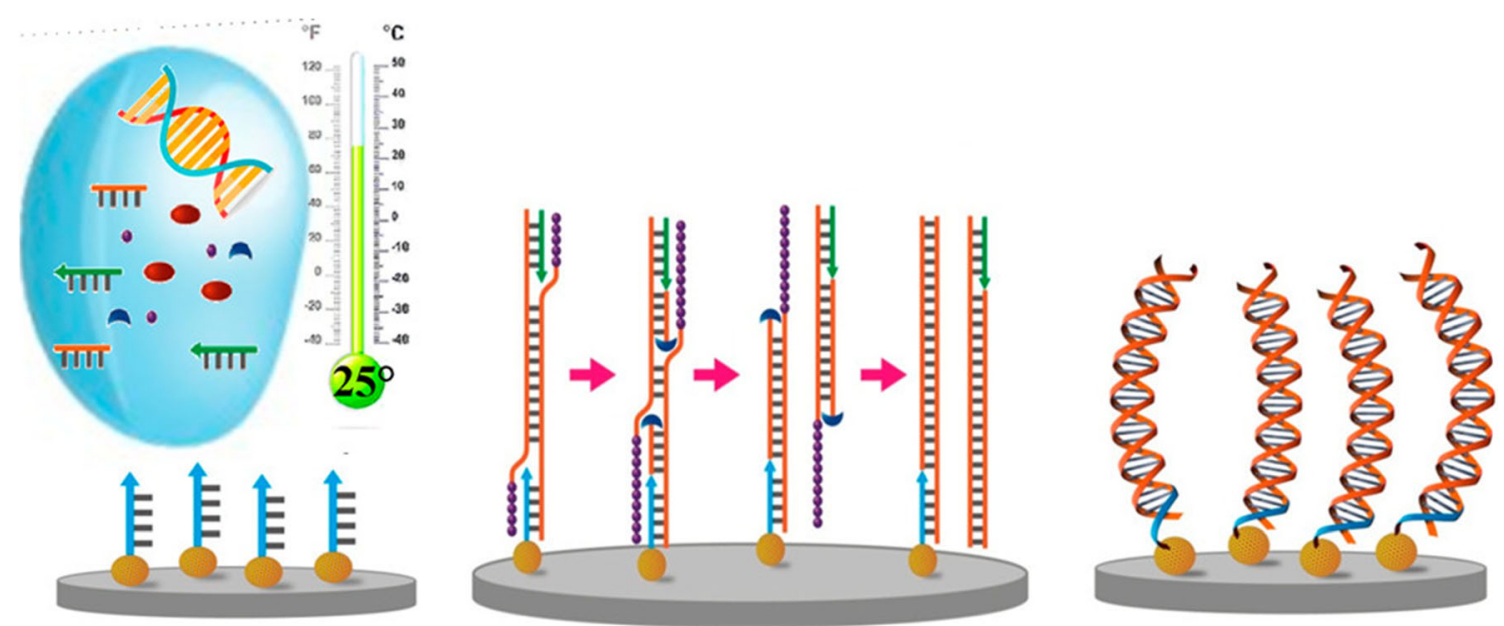

Fig. 8 Detection of Citrus tristeza virus via solid-phase isothermal recombinase polymerase amplification (RPA) using gold nanoparticles coupled with DNA via impedance spectroscopy [93] (Reproduced with permission from publisher)
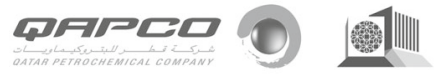
cancer which uses engineered peptides and nanoparticles and other advances like targeted drug delivery [110]. These engineered peptides and nanoparticles may also be a solution to a broad range of viruses and emerging viral pathogens which can potentially be the cause of viral pandemics in the future [101].

Each virus has distinct structural components. However, some of the viruses have common characteristics which provide medical basis for extensive antiviral targeting [101]. This is because of the similarity in patterns of viral genome replication leading to the development of viral replication inhibitors [111]. A number of antiviral drugs belonging to the class of nucleotide and nucleoside analogs have been developed in the form of small molecule inhibitors for treatment of infections, caused by several viruses $[112,113]$. For example, remdesivir, a nucleotide analog, is being explored for treatment of COVID-19 [114]. Nucleotide and nucleoside analogs get incorporated into viral genome and inhibit viral replication.

The first step of virus-cell interaction involves binding of viral proteins to the receptor proteins on the cell membrane of the host cell. Heparan Sulfate (HS) chains, in close proximity to the cell surface, acts as cellular receptor for viruses. Various entry inhibitors can be designed to mimic receptors. Antiviral nanoparticles coated with long and flexible linkers which mimic the Heparin Sulfate Proteo Glycan (HSPG) are designed to inhibit the first step of virus-cell interaction/viral attachment [115]. These particles have characteristic resemblance with that of the strong binding of viral attachment ligands and therefore, they deform the virus irreversibly through generation of strong forces which has been shown to inhibit viruses such as human papilloma, herpes simplex (HSV), respiratory syncytial virus (RSV), dengue, and human immunodeficiency virus (HIV) [107]. Flexible nanogels are also designed to mimic cellular HS, acting as inhibitors to the viral entry [116]. Non-toxic gold nanoparticles (Au NPs) have recently been developed as broad spectrum virus inhibitors and the concept of cyclodextrins, modified with mercaptoundecane sulfonic acid, is developed to mimic Heperan Sulfate which can potentially destroy virus [117].

An alternative way to target virus entry can be spike protein inhibiting antibodies and peptides $[118,119]$. Bacteriophage capsids can act as a binder in multivalent mode due to similarity in spatial arrangement of ligands with the geometry of binding sites of spike protein. Capsids prevent binding to host cell by covering the entire virus envelope thus, inhibiting virus infection [120].

Many viruses are surrounded by the envelops (coating of lipid bilayer; membrane) and therefore, the physiochemical disruption of this envelop may take away the capability of the virus to infect [121]. Majority of viruses causing infectious diseases are membrane bound and therefore, membranes are suggested to be a target for wide range of antiviral activity and thereby inhibiting the membrane fusion process of virus entry [113]. Various antiviral small molecules [122], rigid amphipathic fusion inhibitors (RAFIs) [123], and peptides [124] have appeared to act as a deterrent to virus by inhibiting viral envelopes, for HIV, hepatitis C, dengue, Zika, Ebola, and Chikungunya. Coronaviruses, including COVID-19, are enveloped viruses [125]. From materials science perspective, such strategy of using engineered small molecules can be a potential approach in the development of broad range of antiviral drugs [101].

Nanosponges derived from type-2 epithelial cells present in human lung alveoli or human macrophages can be used to neutralize the virus by exhibiting the same protein receptor, required by SARS-CoV-2 for entry into the host cell and therefore, virus will be unable to infect the host cells [126]. Cell membrane mimicking nanodecoys can be employed to trap and detain viral pathogens at the cell membrane interface and protection against infectious diseases [127]. Biomimetic nanodecoys containing gelatin nanoparticles have been developed to adsorb and inhibit ZIKV replication [128] and similar strategy can be used for the development of treatment options for COVID-19. Virus mimetic nanovesicles, which resemble virus in shape and size and ability to induce immune response, can act as antiviral antigen delivery platforms against enveloped viruses [129]. Micro-physiological systems, derived from stem cells that resemble human tissues, are used to test drug toxicity and efficacy, in vitro. Materials science can help in the development of synthetic scaffolds used in such systems [130, 131]. The m-RNA vaccines require nano-carriers for vaccine encapsulation and stabilization [132, 133]. For example, m-RNA encapsulated with lipid nanoparticles are being explored as vaccine against COVID19 [134]. Microneedle patches, that slowly release the coated material, may be an approach for self-administration of vaccines [132].

Viruses are susceptible to genetic mutation in response to environmental changes and immune response of host cells [135]. Mutation at the drug binding site can result in loss of efficacy of drug [109]. One of the useful approaches for dealing with this problem can be targeting the functions of host cell which can be used for viral replication or other viral functions (Fig. 9) [129]. Host cell functions are not under the control of the virus and therefore, it will be much more difficult for the virus to develop resistance through mutation against antivirals which target host cell functions [22]. From materials science perspective, small molecule inhibitors can be used to target host cell functions. This approach is also verified by the development of various kinase inhibitors $[136,137]$ used in cancer treatment. These inhibitors act by impairing viral traffic in cells and have shown potential against hepatitis $\mathrm{C}$, dengue, and Ebola as these viruses are dependent on particular host cell functions. Kinase inhibitors are repurposed for the use in COVID-19 treatment to reduce lung damaging symptoms by targeting viral life cycle [138].

Cytokine storm is a major cause of mortality in patients suffering from severe COVID-19 pneumonia [106, 139]. 

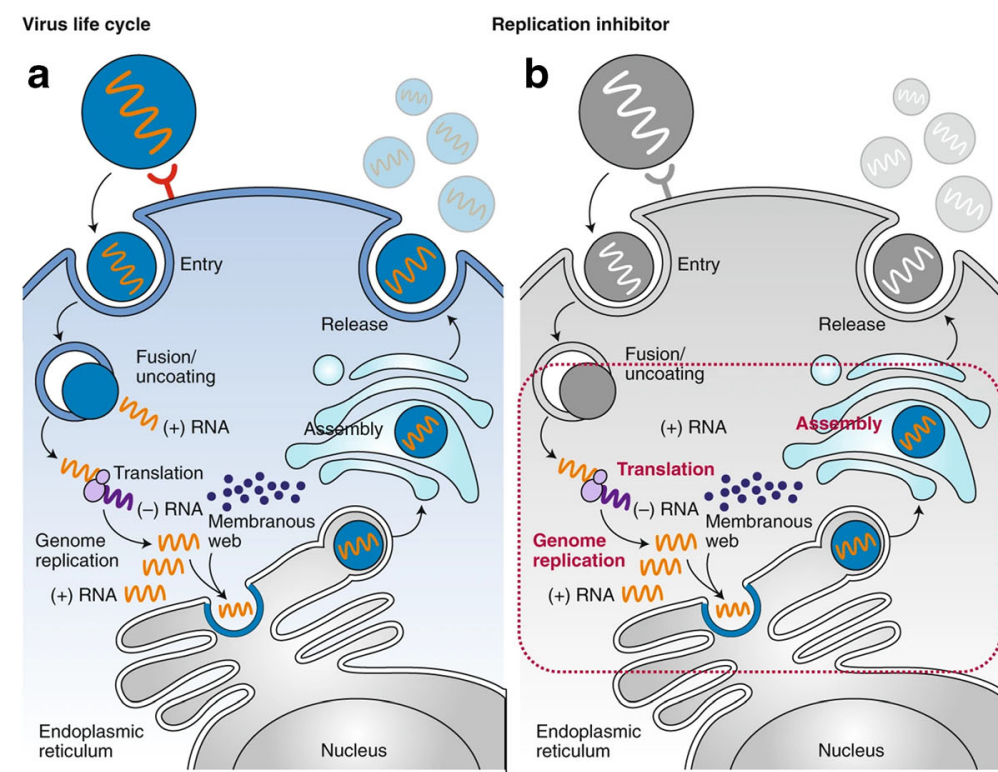

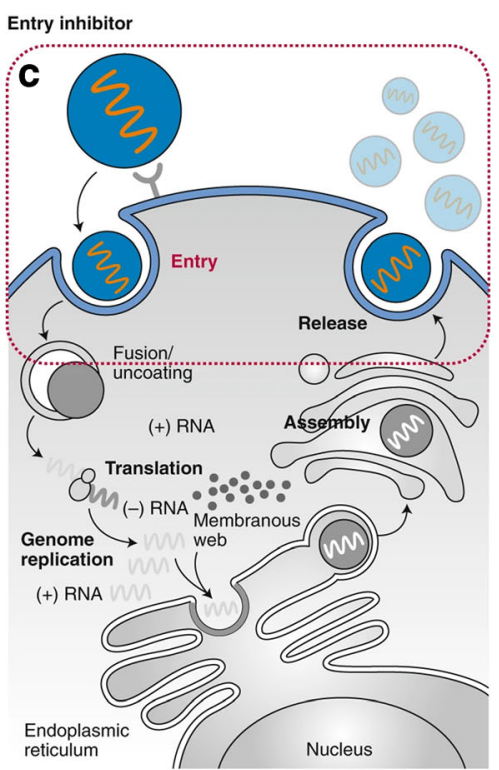

Fig. 9 Role of antiviral drugs to inhibit the virus entry as well as its replication inside the host cell. (a) Viral entry into host cell and subsequent replication using host cell machinery. (b) Site of action of replication inhibitions (antiviral drugs). (c) Site of action entry inhibitors [101] (Reproduced with permission from publisher)
Cytokine storm is an exaggerated immune response against COVID-19 infection that leads to widespread thrombosis and endothelial damage [140-142]. Neutrophil membrane-coated nanoparticles which have been shown to be effective in treatment of inflammatory arthritis can also be used to suppress immune response causing cytokine storm in COVID-19 pneumonia [143]. One of the approaches for the treatment of COVID-19 is the use of neutralizing nano-antibodies. To achieve high concentrations of these neutralizing antibodies, aluminum-based adjuvants are being explored [144-146]. Various co-factors like zinc inhibit enzymes, required for transcription. Nanoparticles can be used to deliver such co-factors to targeted tissues and therefore, be effective in inhibiting viral replication [147].

The pathophysiology of COVID-19 pneumonia is such that it destroys the oxygen exchange capacity of the lungs. In severe COVID-19 pneumonia patients, there is virtually no oxygen exchange possible in damaged lungs. Extra corporal membrane oxygenation (ECMO) is a method to artificially oxygenate the patient's blood by draining it through an ECMO device. The material of gas exchange membrane used in ECMO devices could be improved by using various biocompatible materials, derived from natural human tissues [130].

\section{Challenges and prospects}

The virus can remain active for longer time on tissue paper (3 h), wood/cloth (2 days), glass/bank note (4 days), and stainless steel/plastic (7 days) [148]. Therefore, the decontamination of reusable masks, respirators, surgical tools, etc. is a challenging task to reduce the potential risk of viral infection/transmission. The evolution of various decontamination techniques or selfcleaning coatings is absolutely necessary in this time of medical emergency which also potentially reduces the problems of lack of PPE kits.

The world faced the problem of lack of clinical facilities and quarantine centers during COVID-19 pandemic, therefore, establishing the temporary clinical facilities/quarantine centers is necessary to overcome these problems. In India, the rail coaches and several other places which were not in public use have been converted into temporary quarantine centers with clinical facilities which served as an important assets to fight against COVID-19 pandemic [149]. The rail coaches were equipped with filtration unit, disinfection units, oxygen cylinder, etc. The cost of modification for the coaches was particularly very low [149].

Storage of vaccine for a longer period of time is also one of the challenging tasks. The cold storage plays a crucial role not only in safe keeping of vaccine but also in its distribution. The phase change materials such as salt hydrates in sheets, and dry ice adsorb heat and maintain lower temperature for longer duration and therefore, reduce the overall energy consumption of cold storage [150]. These phase change materials also helps in vaccine transportation in remote location by maintaining lower temperature for several hours.

Nano-carriers directly interact with the biomolecules of COVID-19 virus and host cells which consequently, influence the interaction between them and protect the human beings from viral infection. Nano-molecules also enhance the imaging or drug molecules loading/delivery capability and therefore, such tools should be adapted in the future to improve the 
diagnosis and treatment facilities against COVID-19. Although the nanotechnology has the above mentioned advantages, the nanotoxicity concern cannot be ignored. Therefore, nano-tools must be designed with optimized particle size and dose-dependent manner.

To further study the replication and spread of viruses and the emergence of new viral strains, isolating and purification of target viral strains from biological samples such as blood and saliva are necessary. Therefore, developing cost effective equipment such as hand powered centrifuge is in demand. In addition, dynamics of single virus replication in real-time in cells along with other processes such as RNA replication, formation of protein, and transmission via cell to cell can be studied using high-resolution imaging tools such as timeresolved wide angle $\mathrm{X}$-ray scattering.

As the COVID-19 attacks the respiratory system of the human body, the role of biomedical equipment such as ventilators and ECMO devices is also considerable. Every ventilation system utilize the filters for several purposes like filtration of the supplied gas to the patient, expired gas by the patient, inners of the ventilation track, exhaled pathogens, and nebulizers from the patients to protect the co-workers. These filters can be further modified with a protective antiviral filter system which can inhibit the entry of viruses and also have a selfcleaning ability [22]. Extracorporeal membrane oxygenation (ECMO) devices also suffer from major drawbacks such as complex machinery and non-transferability. In addition, this equipment requires optimized anticoagulation and their titration to avoid bleeding in the patients which is carried by varying the thrombotic (supplements of antithrombin for resistance toward heparin) [151]. Also, changes in the factors concerning the immunity of the patient are also one of the concerns. These issues can be resolved with the development of simple small devices along with the blood pump and oxygenator in a single unit. This development can lead to the portability of the equipment. In addition, by reducing the time for which blood remains outside the body decreases the problems associated with thrombotic variation. ECMO devices consist of gas exchange membranes which are comprised of hollow fibers of silicon rubber and polymeric (polymethylpentene) materials $[152,153]$. These materials have the ability to resist the blood flow to the devices as well as can facilitate the proper gas exchange. These membranes can be employed with better materials such as 3D-printable biocompatible materials [22].

\section{Conclusion}

Materials science plays a pivotal role in antiviral research such as, studying viral biology, their transmission, protection, detection, treatment, and vaccination. COVID-19 has impacted every aspect of life, however, it has also paved a broad opportunity in the field of materials research. From manufacturing to personal protective suits to drug carrier vehicles for the antiviral drug development research, materials science has touched most of the characteristic features for COVID-19related research. Nanomaterial-based microfluidics and immunosensors which are suggested to be point of care systems are slowly becoming standard rapid detection methodology for viral infections. A number of antiviral drugs, utilizing the nanoparticles as carrier, are under in vivo trial.

\section{References}

1. D.D. Richman, R.J. Whitley, F.G. Hayden, Clin. Vir, 4th edn. (ASM Press, Washington, 2016)

2. P.C. Woo, S.K. Lau, C.S. Lam, C.C. Lau, A.K. Tsang, Discovery of seven novel Mammalian and avian coronaviruses in the genus delta coronavirus supports bat coronaviruses as the gene source of alpha coronavirus and beta coronavirus and avian coronaviruses as the gene source of gamma coronavirus and delta coronavirus. J. Virol. 86, 3995-4008 (2012)

3. H. Geng, W. Tan, A novel human coronavirus: Middle East respiratory syndrome human coronavirus. Sciences 56, 683-687 (2013)

4. Y. Lim, Y. Ng, J. Tam, D. Liu, Human coronaviruses: a review of virus-host interactions. Diseases 4, 26 (2016)

5. T. Kuiken, R.A. Fouchier, M. Schutten, Newly discovered coronavirus as the primary cause of severe acute respiratory syndrome. Lancet 362, 263-270 (2003)

6. .H. Wu, E.S.H. Lau, R.C.W. Ma, Secular trends in all-cause and cause-specific mortality rates in people with diabetes in Hong Kong, 2001-2016: a retrospective cohort study, Diabetologia. (2020)

7. Y. Guan, B.J. Zheng, Q.Y. He, X.L. Liu, Z.X. Zhuang, C.L. Cheung, Isolation and characterization of viruses related to the SARS coronavirus from animals in Southern China. Science 302, 276-278 (2003)

8. A. Bermingham, M.A. Chand, C.S. Brown, Severe respiratory illness caused by a novel coronavirus, in a patient transferred to the United Kingdom from the Middle East. Euro Surveillance 17, 20290 (2012)

9. Y. Terada, N. Matsui, K. Noguchi, R. Kuwata, H. Shimoda, T. Soma, M. Mochizuki, K. Maedav, Emergence of pathogenic coronaviruses in cats by homologous recombination between feline and canine coronaviruses. PLoS One 9, e106534 (2014)

10. M.E. Morra, L.V. Thanh, M.G. Kamel, Clinical outcomes of current medical approaches for Middle East respiratory syndrome: a systematic review and meta-analysis. Rev. Med. Virol. 28, e1977 (2018)

11. N.M. Ferguson, D. Laydon, G. Nedjati-Gilani, N. Imai, K. Ainslie, M. Baguelin, S. Bhatia, A. Boonyasiri, Z. Cucunubá, G. Cuomo-Dannenburg, A. Dighe, I. Dorigatti, H. Fu, K. Gaythorpe, W. Green, A. Hamlet, W. Hinsley, L.C. Okell, S.V. Elsland, H. Thompson, R. Verity, E. Volz, H. Wang, Y. Wang, P.G.T. Walker, C. Walters, P. Winskill, C. Whittaker, C.A. Donnelly, S. Riley, A.C. Ghani, Impact of non-pharmaceutical interventions (npis) to reduce covid-19 mortality and healthcare demand (Imperial College COVID-19 Response Team, London, 2020). https://doi.org/10.25561/77482. https://www.imperial.ac.uk/ media/imperialcollege/medicine/sph/ide/gida-fellowships/ 
Imperial-College-COVID19-NPI-modelling-16-03-2020.pdf. Accessed 16 march 2020

12. P. Zhou, X. Yang, X.G. Wang, B. Hu, L. Zhang, W. Zhang, H.R. Si, Y. Zhu, B. Li, C.L. Huang, H.D. Chen, J. Chen, Y. Luo, H. Guo, R.D. Jiang, M.Q. Liu, Y. Chen, X.R. Shen, X. Wang, X.S. Zheng, K. Zhao, Q.J. Chen, F. Deng, L.L. Liu, B. Yan, F.X. Zhan, Y.Y. Wang, G.F. Xiao, Z.L. Shi, A pneumonia outbreak associated with a new coronavirus of probable bat origin. Nature $\mathbf{5 7 9}$, $270(2020)$

13. F. Wu, S. Zhao, B. Yu, Y.M. Chen, W. Wang, Z.G. Song, et al., A new coronavirus associated with human respiratory disease in China. Nature 579, 265-269 (2020)

14. D. Paraskevis, E.G. Kostaki, G. Magiorkinis, et al., Full-genome evolutionary analysis of the novel corona virus (2019-nCoV) rejects the hypothesis of emergence as a result of a recent recombination event, Infect. Genet.Evol. 104212, 79 (2020)

15. M. Madjid, P. Safavi-Naeini, S.D. Solomon, O. Vardeny, Potential effects of coronaviruses on the cardiovascular system: a review. JAMA Cardiol. 5 831-840(831), 840 (2020)

16. Y. Yang, Q.B. Lu, M.J. Liu, et al., Epidemiological and clinical features of the 2019 novel coronavirus outbreak in China. Med Rxiv (2020). https://doi.org/10.1101/2020.02.10.20021675

17. P.K. Bhatraju, B.J. Ghassemieh, M. Nichols, R. Kim, K.R. Jerome, A.K. Nalla, A.L. Greninger, S. Pipavath, M.M. Wurfel, L. Evans, P.A. Kritek, T.E. West, A. Luks, A. Gerbino, C.R. Dale, J.D. Goldman, S. O'Mahony, C. Mikacenic, et al., COVID-19 in critically ill patients in the Seattle region - case series. N. Engl. J. Med. 382, 2012-2022 (2020)

18. T. Guo, Y. Fan, M. Chen, X. Wu, L. Zhang, T. He, H. Wang, J. Wan, X. Wang, Z. Lu, et al., Cardiovascular implications of fatal outcomes of patients with coronavirus disease 2019 (COVID-19). JAMA Cardiol. 5, 811-818 (2020)

19. P. Goyal, J.J. Choi, L.C. Pinheiro, E.J. Schenck, R. Chen, A. Jabri, M.J. Satlin, T.R. Campion Jr., M. Nahid, J.B. Ringel, K.L. Hoffman, M.N. Alshak, H.A. Li, G.T. Wehmeyer, M. Rajan, E. Reshetnyak, N. Hupert, E.M. Horn, F.J. Martinez, R.M. Gulick, M.M. Safford, et al., Clinical characteristics of COVID-19 in New York City. N. Engl. J. Med. 382, 2372-2374 (2020)

20. Q. Ruan, K. Yang, W. Wang, L. Jiang, J. Song, Clinical predictors of mortality due to COVID-19 based on an analysis of data of 150 patients from Wuhan. China. Intensive Care Med. 46, 846-848 (2020)

21. C.M. Riddle, B.J. Buse, W.P. Franks, C.W. Knowler, R.E. Ratner, E.S. Deborah, J.W. Steven, E. Kahn, COVID-19 in People with diabetes: urgently needed lessons from early reports. Diabetes Care 43, 1378-1381 (2020)

22. Z. Tang, N. Kong, X. Zhang, et al., A materials-science perspective on tackling COVID-19. Nat Rev Mater 5, 847-860 (2020)

23. C. Weiss, M. Carriere, L. Fusco, et al., Toward nanotechnologyenabled approaches against the COVID-19 Pandemic. ACS Nano 14, 6383-6406 (2020)

24. M. Hoffmann, H.W. Kleine, S. Schroeder, N. Kruger, T. Herrler, S. Erichsen, T. Schiergens, G. Herrler, H.N. Wu, A. Nitsche, M. Müller, C. Drosten, S. Pohlmann, SARS-CoV-2 cell entry depends on ACE2 and TMPRSS2 and is blocked by a clinically proven protease inhibitor. Cell 181, 271 (2020)

25. S. Berensmeier, Magnetic particles for the separation and purification of nucleic acids. Appl. Microbiol. Biotechnol. 73, 495-504 (2006)

26. S.J. Reinholt, A.J. Baeumner, Microfluidic isolation of nucleic acids. Angew. Chem. Int. Ed. 53, 13988-14001 (2014)

27. M. Unni et al., Engineering magnetic nanoparticles and their integration with microfluidics for cell isolation. J. Colloid Interface Sci. 564, 204-215 (2020)
28. S. Gurunathan, M. Qasim, Y. Choi, J.T. Do, C. Park, K. Hong, H. Song, Antiviral potential of nanoparticles-can nanoparticles fight against coronaviruses? Nanomaterials 10, 1645 (2020)

29. Y.Y. Yu, F. Bu, H. Zhou, Y. Wang, J. Cui, X. Wang, G. Nie, H. Xiao, Biosafety materials: an emerging new research direction of materials science from the COVID-19 outbreak. Mater. Chem. Front. 4, 1930 (2020)

30. M.H. Chua et al., Face masks in the new COVID-19 normal: materials, testing, and perspectives. Research 2020, 7286735 (2020)

31. G.H. Zhang et al., High-performance particulate matter including nanoscale particle removal by a self- powered air filter. Nat. Commun. 11, 1653 (2020)

32. A. Konda, A. Prakash, G.A. Moss, M. Schmoldt, G.D. Grant, S. Guha, Aerosol filtration efficiency of common fabrics used in respiratory cloth masks. ACS Nano 14, 6339-6347 (2020)

33. G. Liu, J. Nie, C. Han, T. Jiang, Z. Yang, Y. Pang, L. Xu, T. Guo, T. Bu, C. Zhang, Z. Lin Wang, ACS Appl. Mater. Interfaces 10, 7126-7133 (2018)

34. E.N. Atab, N. Qaiser, H.S. Badghaish, S.F. Shaikh, M.M. Hussain, A flexible nanoporous template for the design and development of reusable anti-COVID-19 hydrophobic face masks. ACS Nano 14, 7659-7665 (2020)

35. H. Zhong et al., Reusable and recyclable graphene masks with outstanding superhydrophobic and photothermal performances. ACS Nano 14, 6213-6221 (2020)

36. S.K. Adesina, E.O. Akala, Nanotechnology approaches for the delivery of exogenous siRNA for HIV therapy. Mol. Pharm. 12, 4175-4187 (2015)

37. T. Yadavalli, D. Shukla, Role of metal and metal oxide nanoparticles as diagnostic and therapeutic tools for highly prevalent viral infections. Nanomedicine 13, 219-230 (2017)

38. K.A. Prather, C.C. Wang, R.T. Schooley, Reducing transmission of SARS-CoV-2. Science 368, 1422-1424 (2020)

39. K. O'Dowd et al., Face masks and respirators in the fight against the COVID-19 Pandemic: a review of current materials, advances and future perspectives. Materials (Basel Switzerland) 13, 3363 (2020)

40. H.H. Jang, S.R. Ryoo, Y.K. Kim, S. Yoon, H. Kim, S.W. Han, B.S. Choi, D.E. Kim, D.H. Min, Discovery of hepatitis C virus NS3 helicase inhibitors by a multiplexed, high-throughput helicase activity assay based on graphene oxide. Angew. Chem. Int. Ed. 52, 2340-2344 (2013)

41. C. Chen, M. Boota, P. Urbankowski, B. Anasori, L. Miao, J. Jiang, Y. Gogotsi, Effect of glycine functionalization of 2D titanium carbide (MXene) on charge storage. J. Mater. Chem. A 6, 4617-4622 (2018)

42. J. Low, L. Zhang, T. Tong, B. Shen, J. Yu, TiO2/MXene Ti3C2 Composite with excellent photocatalytic $\mathrm{CO} 2$ reduction activity. J. Catal. 361, 255-266 (2018)

43. V.H. Nguyen, B.S. Nguyen, C. Hu, C.C. Nguyen, D.L.T. Nguyen, D.M.T. Nguyen Dinh, D.V.N. Vo, Q.T. Trinh, M. Shokouhimehr, A. Hasani, S.Y. Kim, Q.V. Le, Novel architecture titanium carbide (Ti3C2Tx) MXene cocatalysts toward photocatalytic hydrogen production: a mini-review. Nanomaterials 10, 602 (2020)

44. Z.D. Bolashikov, A.K. Melikov, Methods for air cleaning and protection of building occupants from airborne pathogens. Build. Environ. 44, 1378-1385 (2009)

45. B. Kte'pi, High-efficiency particulate air system|air filtration System (Encyclopedia Britannica, Chicago, 2019)

46. J. Hyun, S.G. Lee, J. Hwang, Application of corona dischargegenerated air ions for filtration of aerosolized virus and inactivation of filtered virus. J. Aerosol Sci. 107, 31-40 (2017)

47. B.U. Lee, K.Y. Yoon, G.N. Bae, J.H. Ji, J. Hwang, Airborne silver nanoparticles from an atomizer as an antimicrobial agent against $\mathrm{E}$ coli Bioaerosols. Proc. Healthy Build., 345-348 (2006) 
48. J. Kim, J. Jang, Inactivation of airborne viruses using vacuum ultraviolet photocatalysis for a flow-through indoor air purifier with short irradiation time. Aerosol Sci. Technol. 52, 557-566 (2018)

49. M. Bodzek, K. Konieczny, M. Rajca, Membranes in water and wastewater disinfection - review. Arch. Environ. Protect. 45, 318 (2019)

50. J.A. Otter, C. Donskey, S. Yezli, S. Douthwaite, S.D. Goldenberg, D.J. Weber, Transmission of SARS and MERS coronaviruses and influenza virus in healthcare settings: the possible role of dry surface contamination. J. Hosp. Infect. 92, 235-250 (2016)

51. Y. Mori, T. Ono, Y. Miyahira, V.Q. Nguyen, T.I.M. Matsui, Antiviral activity of silver nanoparticle:chitosan composites against H1N1 influenza a virus. Nanoscale. Res. Lett. 8, 93 (2013)

52. D. Chakhalian, R.B. Shultz, C.E. Miles, J. Kohn, Opportunities for biomaterials to address the challenges of COVID-19. J. Biomed. Mater. Res. 108(108), 1974-1990 (2020)

53. T. Ishida, Antiviral activities of $\mathrm{Cu} 2+$ ions in viral prevention, replication, RNA degradation, and for antiviral efficacies of lytic virus, ROS-mediated virus, copper chelation. World Sci News 99, 148-168 (2018)

54. J. Kim, M. Yeom, T. Lee, D. Song, et al., Porous gold nanoparticles for attenuating infectivity of influenza a virus. J Nanobiotechnol. 18, 54 (2020)

55. B.B. Hsu, S.Y. Wong, P.T. Hammond, J. Chen, A.M. Klibanov, Mechanism of inactivation of influenza viruses by immobilized hydrophobic polycations. Proc. Natl. Acad. Sci. U. S. A. 108, 6166 (2011)

56. H. Bahadar, F. Maqbool, K. Niaz, M. Abdollahi, Toxicity of nanoparticles and an overview of current experimental models. Iran. Biomed. J. 20, 1-11 (2016)

57. Q. Lin, J.Y.C. Lim, K. Xue, et al., Sanitizing agents for virus inactivation and disinfection. Viewpoints 1, e16 (2020)

58. D.L. Popkin, S. Zilka, M. Dimaano, et al., Cetylpyridinium chloride (CPC) exhibits potent, rapid activity against influenza viruses in vitro and in vivo. Pathog Immun. 2, 252-269 (2017)

59. J. Piret, S. Roy, M. Gagnon, et al., Comparative study of mechanisms of herpes simplex virus inactivation by sodium lauryl sulfate and nlauroylsarcosine. Antimicrob. Agents Chemother. 46, 2933-2942 (2002)

60. D. Vollenbroich, M. Özel, J. Vater, R.M. Kamp, G. Pauli, Mechanism of inactivation of enveloped viruses by the biosurfactant surfactin from Bacillus subtilis. Biologicals. 25, 289-297 (1997)

61. B. Udugama, P. Kadhiresan, H.N. Kozlowski, A. Malekjahani, M. Osborne, V.Y.C. Li, H. Chen, S. Mubareka, J.B. Gubbay, W.C.W. Chan, Diagnosing COVID-19: the disease and tools for detection. ACS Nano 14, 3822-3835 (2020)

62. World Health Organization. Advice on the use of point-of-care immunodiagnostic tests for COVID-19; Scientific Brief, 8 April 2020; World Health Organization, (2020)

63. T. Leïchlé, L. Nicu, T. Alava, MEMS biosensors and COVID-19: missed opportunity. ACS Sensors, 53297-53305 (2020)

64. R. Augustine, A. Hasan, S. Das, R. Ahmed, Y. Mori, T. Notomi, B.D. Kevadiya, A.S. Thakor, Loop-mediated isothermal amplification (LAMP): a rapid, sensitive, specific, and cost-effective point-of-care test for coronaviruses in the context of COVID-19 pandemic. Biology 9, 182 (2020)

65. D. Thompson, Y. Lei, Mini review: recent progress in RT-LAMP enabled COVID-19 detection. Sens. Actuators Rep. 2(1), 100017 (2020)

66. Formlabs. 2020 3D printed test swabs for COVID-19 testing. Retrieved from https://formlabs.com/covid-19-response/covidtest-swabs/.
67. https://www.thehindu.com/news/national/india-brings-downcorona-test-swab-price-to-one-tenth/article31607194.ece. Accessed 17 may 2020.

68. H.C. Yeh, Y.P. Ho, T.H. Wang, Quantum dot-mediated biosensing assays for specific nucleic acid detection. Nanomedicine 1, 115-121 (2005)

69. C. Myhrvold, C.A. Freije, A. Catherine, J.S. Gootenberg, O.O. Abudayyeh, H.C. Metsky, A.F. Durbin, M.J. Kellner, A.L. Tan, L.M. Paul, L.A. Parham, K.F. Garcia, K.G. Barnes, B. Chak, A. Mondini, M.L. Nogueira, S.S. Isern, S.F. Michael, I. Lorenzana, N.L. Yozwiak, B.L. MacInnis, I.G. Bosch, L. Gehrke, F. Zhang, P.C. Sabeti, Field-deployable viral diagnostics using CRISPRCas13. Science 360, 444-448 (6387)

70. P. Gill, A. Ghaemi, Nucleic acid isothermal amplification technologies: a review. Nucleosides Nucleotides Nucleic Acids 27, 224 $243(2008)$

71. Y. Zhao, F. Chen, Q. Li, L. Wang, C. Fan, Isothermal amplification of nucleic acids. Chem. Rev. 115, 12491-12545 (2015)

72. Y. Hong, Y.M. Huh, D.S. Yoon, J. Yang, Nanobiosensors based on localized surface plasmon resonance for biomarker detection. J. Nanomater. 2012, 1-13 (2012)

73. P. Guo, C. Wei, Quantum dots for robust and simple assays using single particles in nanodevices. Nanomedicine 1, 122-124 (2005)

74. I. Astuti, Ysrafil, Severe acute respiratory syndrome coronavirus 2 (SARS-CoV-2): an overview of viral structure and host response. Diabetes Metab. Syndr. Clin. Res. Rev. 14, 407-412 (2020)

75. A. Pandey, A.N. Nikam, S.P. Mutalik, G. Fernandes, A.B. Shreya, B.S. Padya, R. Raychaudhuri, S. Kulkarni, R. Prassl, S. Subramanian, A. Korde, S. Mutalik, Architectured therapeutic and diagnostic nanoplatforms for combating SARS-CoV-2: role of inorganic, organic, and radioactive materials. ACS Biomater.Sci. Eng. 7(1), 31-54 (2021)

76. S. Somvanshi, P. Kharat, T. Saraf, S. Somwanshi, S. Shejul and K. Jadhav, Multifunctional nano-magnetic particles assisted viral rnaextraction protocol for potential detection of COVID-19. Mater Res Innov, 1-6 (2020).

77. Cost-effective kit used for coronavirus tests launched; Business Standard India; May 21, 2020

78. M.J. Kellner, J.G. Koob, J.S. Gootenberg, et al., SHERLOCK: nucleic acid detection with CRISPR nucleases. Nat. Protoc. 14, 2986-3012 (2019)

79. Z. Zhang, Y. Cong, Y. Huang, X. Du, Nanomaterials-based electrochemical immunosensors. Micromachines 10, 397 (2019)

80. I.L.J. Celine, Justino, C.D. Armando, A.P. Teresa R. Santos, Chapter Three - Immunosensors in clinical laboratory diagnostics, Editor(s): Gregory S. Makowski, Advances in Clinical Chemistry, Elsevier 73, 65-108 (2016)

81. M. Aizawa, Immunosensors for clinical analysis, Editor(s): Herbert E. Spiegel, Advances in Clinical Chemistry, Elsevier 31, 247-275 (1994)

82. J.M. Van Emon, 1.49 - Immunoassays in biotechnology, Editor(s): Murray Moo-Young, Comprehensive Biotechnology (2nd Edition), Academic Press, 659-667 (2011)

83. J. Ju, W. Chen, In situ growth of surfactant-free gold nanoparticles on nitrogen-doped graphene quantum dots for electrochemical detection of hydrogen peroxide in biological environments. Anal. Chem. 87, 1903-1910 (2015)

84. Z. Fan, S. Li, F. Yuan, L. Fan, Fluorescent graphene quantum dots for biosensing and bioimaging. RSC Adv. 5, 19773-19789 (2015)

85. Y. Yang et al., A novel label-free electrochemical immunosensor based on functionalized nitrogen-doped graphene quantum dots for carcinoembryonic antigen detection. Biosens.Bioelectron 90, 31-38 (2017)

86. O. Parlak, A. İncel, L. Uzun, A.P. Turner, A. Tiwari, A. Structuring, nanoparticles on two-dimensional MoS2 nanosheets 
for electrochemical glucose biosensors. Biosens.Bioelectron. 89, 545-550 (2017)

87. M. Chen et al., An electrochemical DNA biosensor based on nitrogen-doped graphene/Au nanoparticles for human multidrug resistance gene detection. Biosens.Bioelectron 85, 684-691 (2016)

88. J.A. Hansen et al., Quantum-dot/aptamer-based ultrasensitive multi-analyte electrochemical biosensor. J. Am. Chem. Soc. 128, 2228-2229 (2006)

89. R. Haldavnekar, K. Venkatakrishnan, B. Tan, Non plasmonic semiconductor quantum SERS probe as a pathway for in vitro cancer detection. Nat. Commun. 9, 3065 (2018)

90. N.A. Kumar et al., Polyaniline-grafted reduced graphene oxide for efficient electrochemical supercapacitors. ACS Nano 6, 1715$1723(2012)$

91. D. Zhai et al., Highly sensitive glucose sensor based on Pt nanoparticle/polyaniline hydrogel heterostructures. ACS Nano 7, 3540-3546 (2013)

92. A.D. Chowdhury, A. De, C.R. Chaudhuri, K. Bandyopadhyay, P. Sen, Label free polyaniline based impedimetric biosensor for detection of E. coli O157: H7 Bacteria. Sensors Actuators B Chem. 171, 916-923 (2012)

93. A.D. Chowdhury, R. Gangopadhyay, A. De, Highly sensitive electrochemical biosensor for glucose, DNA and protein using gold-polyanilinenanocomposites as a common matrix. Sensors Actuators B Chem. 190, 348-356 (2014)

94. B. Zhang et al., Diagnosis of Zika virus infection on a nanotechnology platform. Nat. Med. 23, 548-550 (2017)

95. F. Patolsky, G. Zheng, O. Hayden, M. Lakadamyali, X. Zhuang, C.M. Lieber, Electrical detection of single viruses. Proc.Natl.Acad.Sci U S A. 101(39), 14017-14022 (2004)

96. A.D. Chowdhury, K. Takemura, T.C. Li, et al., Electrical pulseinduced electrochemical biosensor for hepatitis $\mathrm{E}$ virus detection. Nat. Commun. 10, 3737 (2019)

97. M. Baaske, M. Foreman, F. Vollmer, Single-molecule nucleic acid interactions monitored on a label-free microcavity biosensor platform. Nat. Nanotech 9, 933-939 (2014)

98. X. Weng, S. Neethirajan, Immunosensor based on antibodyfunctionalized MoS2 for rapid detection of avian coronavirus on cotton thread. IEEE Sensors J. 18(11), 4358-4363 (2018)

99. T.R. Holford, F. Davis, S.P. Higson, Recent trends in antibody based sensors. Biosens. Bioelectron. 34(1), 12-24 (2012)

100. C. Huang, Y. Wang, X. Li, L. Ren, J. Zhao, Y. Hu, L. Zhang, G. Fan, J. Xu, X. Gu, Z. Cheng, T. Yu, J. Xia, Y. Wei, W. Wu, X. Xie, W. Yin, H. Li, M. Liu, Y. Xiao, H. Gao, L. Guo, J. Xie, G. Wang, R. Jiang, Z. Gao, Q. Jin, J. Wang, B. Cao, Clinical features of patients infected with 2019 novel coronavirus in Wuhan, China. Lancet 395, 497-506 (2020)

101. S. Aggarwal, T.N. Garcia, G. Aggarwal, C. Lavie, G. Lippi, B.M. Henry, Clinical features, laboratory characteristics, and outcomes of patients hospitalized with coronavirus disease 2019 (COVID19): early report from the United States. Diagnosis 7(2), 91-96 (2020)

102. G. Seo, G. Lee, M.J. Kim, S.H. Baek, M. Choi, K.B. Ku, C.S. Lee, S. Jun, D. Park, H.G. Kim, S.J. Kim, J.O. Lee, B.T. Kim, E.C. Park, S.I. Kim, Rapid Detection of COVID-19 causative virus (SARS-CoV-2) in human nasopharyngeal swab specimens using field-effect transistor-based biosensor. ACS Nano 14, 5135-5142 (2020)

103. V.S. Sivasankarapillai, A.M. Pillai, A. Rahdar, A.P. Sobha, S.S. Das, A.C. Mitropoulos, M.H. Mokarrar, G.Z. Kyzas, On facing the SARS-CoV-2 (COVID-19) with combination of nanomaterials and medicine: possible strategies and first challenges. Nanomaterials 10(5), 852 (2020)
104. M.M. Costa, A.E. Muñiz, C. Nogués, L. Barrios, E. Ibáñez, A. Merkoçi, Simple monitoring of cancer cells using nanoparticles. Nano Lett. 12, 4164-4171 (2012)

105. M. Khater, A. Escosura-Muñiz, L. Altet, A. Merkoçi, In situ plant virus nucleic acid isothermal amplification detection on gold nanoparticle-modified electrodes. Anal.Chem 91, 4790-4796 (2019)

106. A.S. Lauring, J. Frydman, R. Andino, The role of mutational robustness in RNA virus evolution. Nat. Rev. Microbiol. 11, 327 336 (2013)

107. A. Adalja, T. Inglesby, Broad-spectrum antiviral agents: a crucial pandemic tool. Expert Rev. Anti-infective Ther 17, 467-470 (2019)

108. E.D. Clercq, G. Li, Approved antiviral drugs over the past 50 years. Clin. Microbiol. Rev. 29, 695-747 (2016)

109. N. Cho, J. Glenn, Materials science approaches in the development of broad-spectrum antiviral therapies. Nat. Mater. 19, 813$816(2020)$

110. R. Soudy, N. Byeon, Y. Raghuwanshi, S. Ahmed, A. Lavasanifar, K. Kaur, Engineered peptides for applications in cancer-targeted drug delivery and tumor detection. Mini-Rev. Med. Chem. 17, 1696-1712 (2017)

111. E. Clercq, Antivirals and antiviral strategies. Nat. Rev. Microbiol. 2, 704-720 (2004)

112. T. Warren, J. Wells, R. Panchal, K. Stuthman, N. Garza, T. Van, L. Dong, C. Retterer, B. Eaton, G. Pegoraro, S. Honnold, S. Bantia, P. Kotian, X. Chen, B. Taubenheim, L. Welch, D. Minning, Y. Babu, W. Sheridan, S. Bavari, Protection against filovirus diseases by a novel broad-spectrum nucleoside analogue BCX4430. Nature 508, 402-405 (2014)

113. Y. Furuta, B.B. Gowen, K. Takahashi, K. Shiraki, D.F. Smee, D.L. Barnard, Favipiravir (T-705), a novel viral RNA polymerase inhibitor. Antivir. Res. 100, 446-454 (2013)

114. J. Grein, N. Ohmagari, D. Shin, G. Diaz, E. Asperges, A. Castagna, E. Nicastri, Compassionate use of remdesivir for patients with severe Covid-19. N. Engl. J. Med. 382, 2327-2336 (2020)

115. V. Cagno, P. Andreozzi, M. D'Alicarnasso, P. Jacob Silva, M. Mueller, M. Galloux, R. Le Goffic, S. Jones, M. Vallino, J. Hodek, J. Weber, S. Sen, E. Janeček, A. Bekdemir, B. Sanavio, C. Martinelli, M. Donalisio, M. RameixWelti, J. Eleouet, Y. Han, L. Kaiser, L. Vukovic, C. Tapparel, P. Král, S. Krol, D. Lembo, F. Stellacci, Broad-spectrum non-toxic antiviral nanoparticles with a virucidal inhibition mechanism. Nat. Mater. 17(2), 195-203 (2017)

116. P. Dey, T. Bergmann, J.L. Cuellar-Camacho, S. Ehrmann, M.S. Chowdhury, M. Zhang, I. Dahmani, R. Haag, W. Azab, Multivalent flexible nanogels exhibit broad-spectrum antiviral activity by blocking virus entry. ACS Nano 12(7), 6429-6442. https://doi.org/ (2018). https://doi.org/10.1021/acsnano.8b01616

117. S.T. Jones et al., Modified cyclodextrins as broad-spectrum antivirals. Sci. Adv. 6, eaax9318 (2020)

118. N.C. Wu, I.A. Wilson, Structural insights into the design of novel anti-influenza therapies. Nat. Struct. Mol. Biol. 25, 115-121 (2018)

119. R.U. Kadam et al., Potent peptidic fusion inhibitors of influenza virus. Science 358, 496-502 (2017)

120. D. Lauster, S. Klenk, K. Ludwig, S. Nojoumi, S. Behren, L. Adam, et al., Phage capsid nanoparticles with defined ligand arrangement block influenza virus entry. Nat. Nanotechnol. 15(5), 373-379 (2020)

121. F. Vigant, N. Santos, B. Lee, Broad-spectrum antivirals against viral fusion. Nat. Rev. Microbiol. 13(7), 426-437 (2015)

122. M. Wolf, A. Freiberg, T. Zhang, Z. Akyol-Ataman, A. Grock, P. Hong, J. Li, N. Watson, A. Fang, H. Aguilar, M. Porotto, A. Honko, R. Damoiseaux, J. Miller, S. Woodson, S. 
Chantasirivisal, V. Fontanes, O. Negrete, P. Krogstad, A. Dasgupta, A. Moscona, L. Hensley, S. Whelan, K. Faull, M. Holbrook, M. Jung, B. Lee, A broad-spectrum antiviral targeting entry of enveloped viruses. Proc. Natl. Acad. Sci. 107(7), 3157$3162(2010)$

123. M. St Vincent, C. Colpitts, A. Ustinov, M. Muqadas, M. Joyce, N. Barsby, R. Epand, R. Epand, S. Khramyshev, O. Valueva, V. Korshun, D. Tyrrell, L. Schang, Rigidamphipathic fusion inhibitors, small molecule antiviral compounds against enveloped viruses. Proc. Natl. Acad. Sci. 107(40), 17339-17344 (2010)

124. J.A. Jackman, V.V. Costa, S. Park, et al., Therapeutic treatment of Zika virus infection using a brain-penetrating antiviral peptide. Nat. Mater. 17, 971-977 (2018). https://doi.org/10.1038/s41563018-0194-2

125. D. Schoeman, B.C. Fielding, Coronavirus envelope protein: current knowledge. Virol. J. 16, 69 (2019). https://doi.org/). https:// doi.org/10.1186/s12985-019-1182-0

126. Q. Zhang, A. Honko, J. Zhou, H. Gong, S. Downs, J. Vasquez, R. Fang, W. Gao, A. Griffiths, L. Zhang, Cellular nanosponges inhibit SARS-CoV-2 infectivity. Nano Lett. 20(7), 5570-5574 (2020)

127. L. Rao, R. Tian, X. Chen, Cell-membrane-mimicking nanodecoys against infectious diseases. ACS Nano 14(3), 2569-2574 (2020)

128. L. Rao, W. Wang, Q.F. Meng, M. Tian, B. Cai, Y. Wang, et al., A biomimetic nanodecoy traps zika virus to prevent viral infection and fetal microcephaly development. Nano Lett. 19(4), 2215$2222(2018)$

129. P. Zhang, Y. Chen, Y. Zeng, C. Shen, R. Li, Z. Guo, et al., Virusmimetic nanovesicles as a versatile antigen-delivery system. Proc. Natl. Acad. Sci. 112(45), E6129-E6138 (2015)

130. E.A. Aisenbrey, W.L. Murphy, Synthetic alternatives to matrigel. Nat. Rev. Mater. 5, 539-551 (2020) 1-13

131. M.J. Kratochvil, A.J. Seymour, T.L. Li, S.P. Paşca, C.J. Kuo, S.C. Heilshorn, Engineered materials for organoid systems. Nat. Rev. Mater. 4(9), 606-622 (2019)

132. McHugh, K. J., Jing, L., Severt, S. Y., Cruz, M., Sarmadi, M., Jayawardena, H. S. N., ... \& Graf, T. (2019). Biocompatible nearinfrared quantum dots delivered to the skin by microneedle patches record vaccination. Sci. Transl. Med., 11(523).

133. R.S. Riley, C.H. June, R. Langer, M.J. Mitchell, Delivery technologies for cancer immunotherapy. Nat. Rev. Drug Discov. 18(3), 175-196 (2019)

134. Vogel, A. et al. A prefusion SARS-CoV-2 spike RNA vaccine is highly immunogenic and prevents lung infection in non-human primates. Preprint at bioRxiv https://doi.org/10.1101/2020.09.08. 280818 (2020)

135. Cerutti, F., Giorda, F., Grattarola, C., Mignone, W., Beltramo, C., Keck, N., Lorusso, A., Francesco, G., Renzo, L., Guardo, G., Goria, M., Masoero, L., Acutis, P., Casalone, C., Peletto, S., Lin, W., Cui, H., Teng, Q., Li, L., Shi, Y., Li, X., Yang, J., Liu, Q., Deng, J., Li, Z., Moniruzzaman, M., Weinheimer, A., MartinezGutierrez, C., Aylward, F., Vanmechelen, B., Vergote, V., Merino, M., Verbeken, E., Maes, P., Escalera-Zamudio, M., Golden, M., Gutiérrez, B., Thézé, J., Keown, J., Carrique, L., Bowden, T., Pybus, O., McAuley, A., Kuiper, M., Durr, P., Bruce, M., Barr, J., Todd, S., Au, G., Blasdell, K., Tachedjian, M., Lowther, S., Marsh, G., Edwards, S., Poole, T., Layton, R., Riddell, S., Drew, T., Druce, J., Smith, T., Broderick, K., Vasan, S., Otto, G., Otto, G., Villabona-Arenas, C., Hanage, W., Tully, D., Leeks, A., West, S. and Clyde, D., 2020.Viral evolution - latest research and news | Nature. [online] Nature.com. Available at: $<$ https://www.nature.com/subjects/viral-evolution\#: $\sim:$ text $=$ Viral $\% 20$ evolution $\% 20$ refers $\% 20$ to $\% 20$ the, sizes $\% 2 \mathrm{C} \% 20$ viruses $\% 20$ can $\% 20$ evolve\%20rapidly.> [Accessed 12 December 2020].

136. Bekerman, E., Neveu, G., Shulla, A., Brannan, J., Pu, S. Y., Wang, S., ... \&Govero, J. (2017). Anticancer kinase inhibitors impair intracellular viral trafficking and exert broad-spectrum antiviral effects. JClin Invest, 127(4), 1338-1352.

137. S. Schor, S. Einav, Repurposing of kinase inhibitors as broadspectrum antiviral drugs. DNA Cell Biol. 37(2), 63-69 (2018)

138. E. Weisberg, A. Parent, P.L. Yang, et al., Repurposing of kinase inhibitors for treatment of COVID-19. Pharm. Res. 37, 167 (2020)

139. S.F. Pedersen, Y.C. Ho, SARS-CoV-2: a storm is raging. J. Clin. Invest. 130(5), 2202-2205 (2020)

140. K.J. Huang, I.J. Su, M. Theron, Y.C. Wu, S.K. Lai, C.C. Liu, H.Y. Lei, An interferon- $\gamma$-related cytokine storm in SARS patients. J. Med. Virol. 75(2), 185-194 (2005)

141. A.L. Rothman, Immunity to dengue virus: a tale of original antigenic sin and tropical cytokine storms. Nat. Rev. Immunol. 11(8), 532-543 (2011)

142. J.R. Tisoncik, M.J. Korth, C.P. Simmons, J. Farrar, T.R. Martin, M.G. Katze, Into the eye of the cytokine storm. Microbiol. Mol. Biol. Rev. 76(1), 16-32 (2012)

143. Q. Zhang, D. Dehaini, Y. Zhang, J. Zhou, X. Chen, L. Zhang, et al., Neutrophil membrane-coated nanoparticles inhibit synovial inflammation and alleviate joint damage in inflammatory arthritis. Nat. Nanotechnol. 13(12), 1182-1190 (2018)

144. Zhu, F. C., Li, Y. H., Guan, X. H., Hou, L. H., Wang, W. J., Li, J. X., ... \& Jia, S. Y. (2020). Safety, tolerability, and immunogenicity of a recombinant adenovirus type-5 vectored COVID-19 vaccine: a dose-escalation, open-label, non-randomised, first-in-human trial. The Lancet., 95:1845-1854

145. Gao, Q., Bao, L., Mao, H., Wang, L., Xu, K., Yang, M., ... \&Gao, H. (2020). Development of an inactivated vaccine candidate for SARS-CoV-2. Science, 69:77-81

146. P.J. Hotez, D.B. Corry, U. Strych, M.E. Bottazzi, COVID-19 vaccines: neutralizing antibodies and the alum advantage. Nat. Rev. Immunol. 20, 399-400 (2020) 1-2

147. N. Kaushik, C. Subramani, S. Anang, R. Muthumohan, B. Nayak, C.T. Ranjith-Kumar, M. Surjit, Zinc salts block hepatitis E virus replication by inhibiting the activity of viral RNA-dependent RNA polymerase. J. Virol. 91(21), JVI.00754-17 (2017)

148. A.W.H. Chin, J.T.S. Chu, M.R.A. Perera, K.P.Y. Hui, H.-L. Yen, M.C.W. Chan, M. Peiris, L.L.M. Poon, Stability of SARSCoV-2 in different environmental conditions. Lancet Microbe. 1, e10 (2020)

149. https://economictimes.indiatimes.com/industry/transportation/ railways/anand-viharrailway-station-is-now-fully-turned-into-acovid-care-facility/not-thatcheap/slideshow/76423323.cms. Accessed 17 June 2020.

150. https://asunow.asu.edu/20201201-solutions-cold-storage-crucialcovid-19-vaccine-distribution. Accessed 1 Dec 2020.

151. M.M. Chlebowski, S. Baltagi, M. Carlson, M. et al. Clinical controversies in anticoagulation monitoring and antithrombin supplementation for ECMO. Crit. Care 24, 19 (2020)

152. T. Motomura, T. Maeda, S. Kawahito, T. Matsui, S. Ichikawa, H. Ishitoya, M. Kawamura, T. Shinohara, K. Sato, Y. Kawaguchi, D. Taylor, D. Oestmann, J. Glueck, Y. Nosé, Development of silicone rubber hollow fiber membrane oxygenator for ECMO. Artif. Organs 27, 1050-1053 (2003)

153. S. Agati, G. Ciccarello, N. Fachile, et al., DIDECMO: a new polymethylpentene oxygenator for pediatric extracorporeal membrane oxygenation. ASAIO J. (American Society for Artificial Internal Organs : 1992) 52(5), 509-512 (2006) 